\title{
Nickel-Catalyzed Hydroarylation of Alkynes Under Reductive Conditions with Aryl Bromides and Water
}

\section{Supporting information}

E. Ryan Barber, Hannah M. Hynds, Claudia P. Stephens, Holli E. Lemons, Emily T.

Fredrickson, Dale J. Wilger*

(Email: dwilger@samford.edu)

Department of Chemistry and Biochemistry, Samford University, Propst Hall, Birmingham, AL 35229

\section{Table of Contents}

I. Figure S1. Images for the General Procedure A for

Reaction Optimization and GC-MS Analysis__ S2

II. Figure S2. Representative Crude GC-MS Chromatogram__ S3

III. Figure S3. Images for the General Procedure B for

Large Scale Reactions and Isolated Yields

IV. Figure S4. Images for the General Procedure C for the

Decagram-Scale Synthesis of $\mathbf{3 a}$

V. Table S1. Optimization of the Zn Source S6

VI. Table S2. Aryl Bromides Used Throughout the Hydroarylation Study S7

VII. Table S3. Effects of Precatalyst Loading S8

VIII. Figure S5. Assignment of the stereochemistry for $\mathbf{3 k}$ and $\mathbf{3 l}$ S9

IX. Figure S6. Assignment of the stereochemistry for $\mathbf{3 q}$ S11

X. References S12

XI. ${ }^{1} \mathrm{H}$ and ${ }^{13} \mathrm{C}$ Spectra 


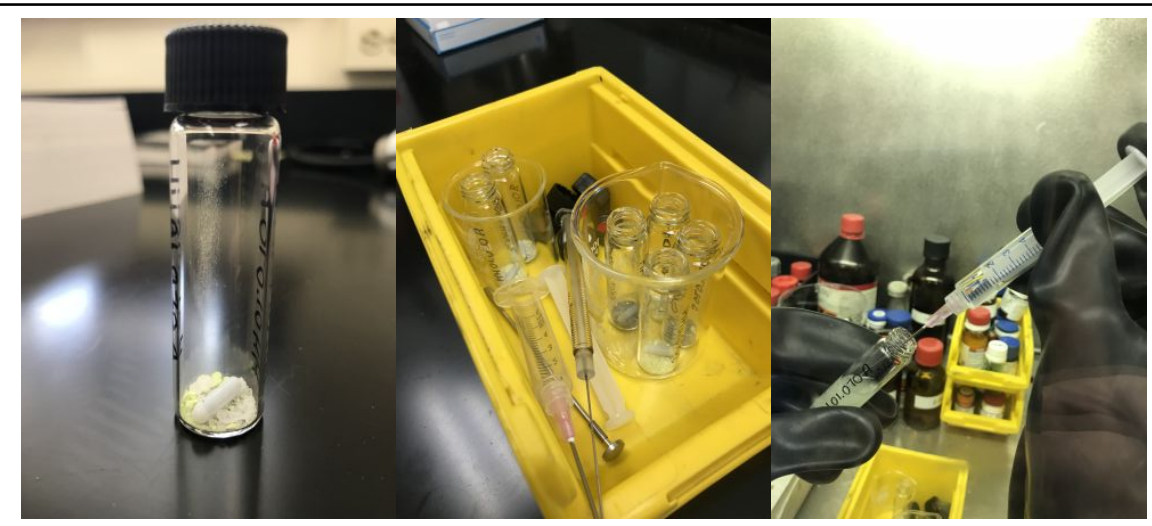

(Left) The $\mathrm{Ni}\left(\right.$ phen) $\mathrm{Cl}_{2}$ precatalyst, $\mathrm{Zn}$, and diphenylacetylene (1a) can be weighed out into a 2 dram vial with a magnetic stir bar outside of an inert-atmosphere glovebox. (Center) The vials and syringes are brought into the $\mathrm{N}_{2}$-filled glovebox uncapped. (Right) The solvent ( $5 \mathrm{~mL}$ DMF) is added via syringe.

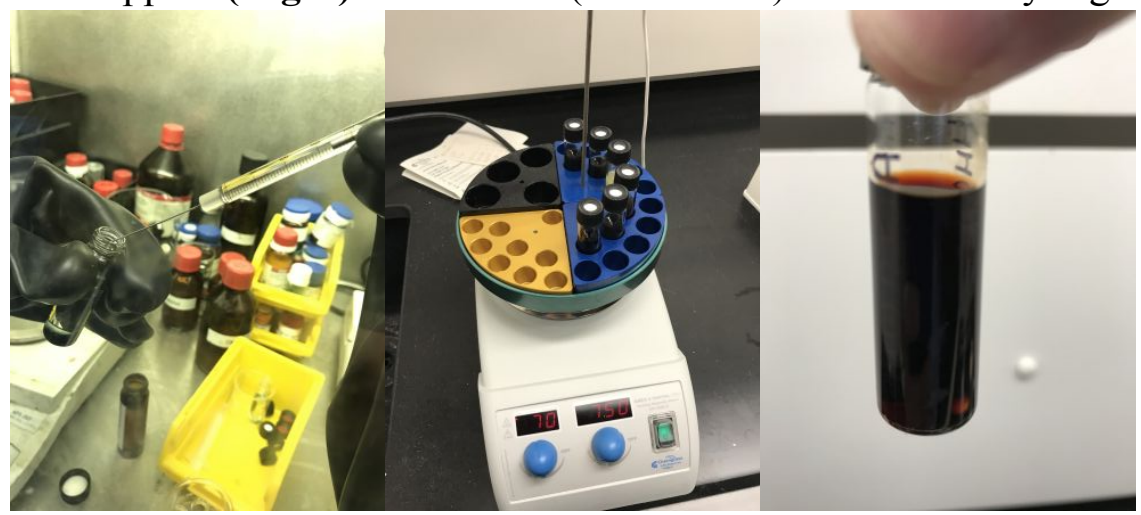

(Left) ortho-Bromotoluene (2a) is added via syringe after the solvent. (Center) The vials are sealed with septum caps, removed from the glove-box, and water is added via syringe. The vials are stirred in an aluminum heating block set to $70{ }^{\circ} \mathrm{C}$. (Right) Within a short period of time stirring at $70{ }^{\circ} \mathrm{C}$, the reactions turn a characteristic red color. This color persists until the reactions are essentially complete, and this color can serve as a qualitative measure of conversion.

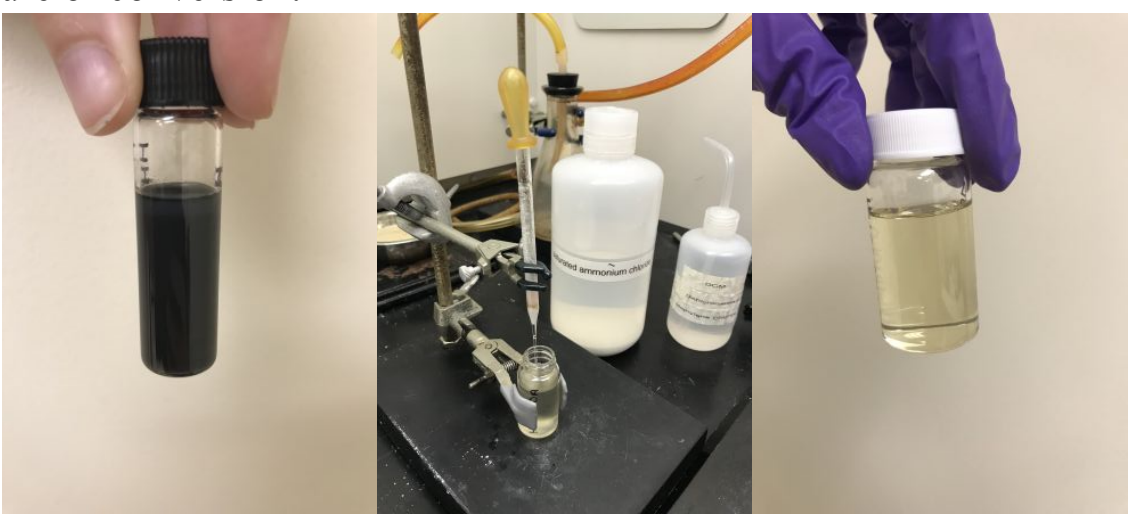

(Left) After stirring for approximately 8-12 hours, the reactions turn a dark grey/black color. This typically indicates the reaction is complete. Reactions may be stirred up to 24 hours, but considerably longer reaction times ( $>48$ hours) can lead to product decomposition. The reaction mixture is added to sat. aq. $\mathrm{NH}_{4} \mathrm{Cl}(5 \mathrm{~mL})$, and then extracted with DCM $(3 \times 5 \mathrm{~mL})$ (not shown). (Center) The organic fractions are passed through a pipette containing silica gel. (Right) The combined organic fractions are treated with internal standard (paraxylene), mixed thoroughly, and diluted for GC-MS analysis. 
II. Figure S2. Representative Crude GC-MS Chromatogram (with Internal Standard)

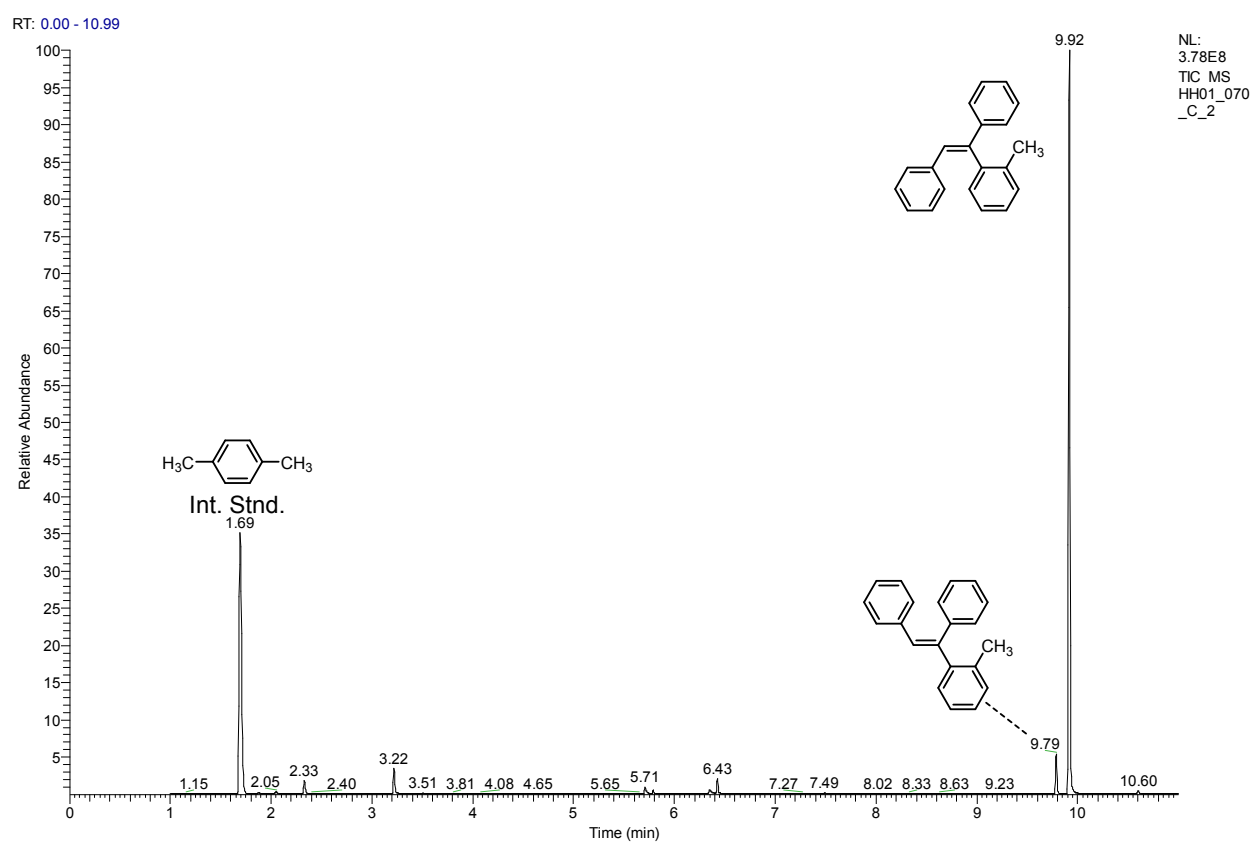

Note: The hydrodehalogenation product (toluene) is below the mass detection limit $(100 \mathrm{~m} / \mathrm{z})$ in this example. When other aryl bromides are used this byproduct is observed and it must be removed during chromatography (if the compound is not volatile). 
III. Figure S3. Images for the General Procedure B for Large Scale Reactions and Isolated Yields

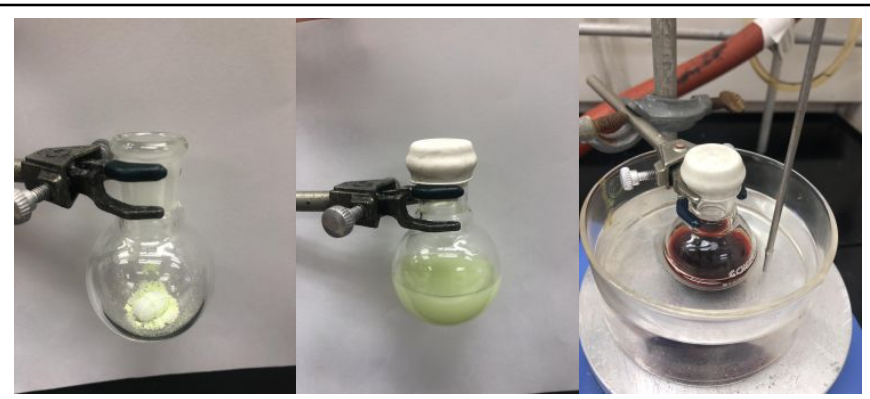

(Left) The $\mathrm{Ni}\left(\right.$ phen) $\mathrm{Cl}_{2}$ precatalyst, $\mathrm{Zn}$, and diphenylacetylene (1a) can be weighed out into a $25 \mathrm{~mL}$ round bottom with a magnetic stir bar outside of an inert-atmosphere glovebox. (Center) The flask is brought into a glovebox, and the solvent ( $5 \mathrm{~mL}$ DMF) is added via syringe. The aryl bromide is also typically added inside a glovebox, although purging with $\mathrm{N}_{2}$ and adding liquid reagents via syringe is generally equally effective. Water is added via syringe outside of the glovebox. (Right) The round bottom flask is heated in an oil bath set to $70{ }^{\circ} \mathrm{C}$. Within a short period of time stirring at $70{ }^{\circ} \mathrm{C}$, the reactions turn a characteristic red/orange color. This color persists until the reactions are essentially complete. A similar color was observed for all aryl halides which successfully reacted under the hydroarylation conditions.

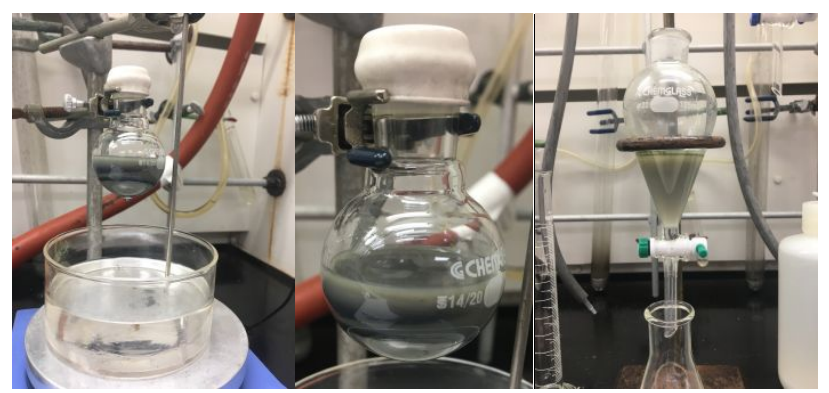

(Left) After stirring for approximately 8-12 hours the reactions turn a dark grey/black color. This typically indicates the reaction is complete. (Center) A magnified view of the reaction after completion. (Right) The reaction is added to a $125 \mathrm{~mL}$ separatory flask which contains sat. aq. $\mathrm{NH}_{4} \mathrm{Cl}(20 \mathrm{~mL})$.

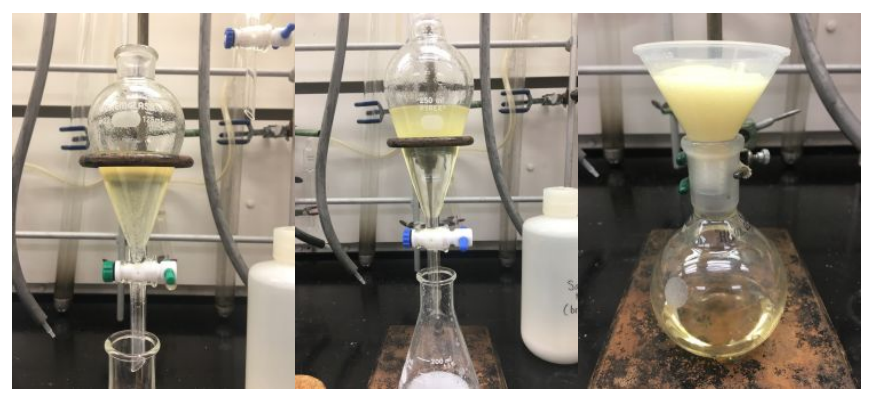

(Left) The organic material was extracted with ethyl acetate $(3 \times 20 \mathrm{~mL})$. (Center) the combined organic fractions are transferred to a $250 \mathrm{~mL}$ separatory funnel and washed with deionized $\mathrm{H}_{2} \mathrm{O}(2 \times 60 \mathrm{~mL})$ and brine $(1 \mathrm{x} 60 \mathrm{~mL})$. This step is to remove residual DMF and is important for adequate separation during chromatography. (Right) The organic solution is then dried with anhydrous sodium sulfate, collected in a 250 $\mathrm{mL}$ round bottom flask, and concentrated via rotary evaporation. The product was isolated after column chromatography on silica gel $(3 \times 20 \mathrm{~cm})$ using hexanes as an eluent. 

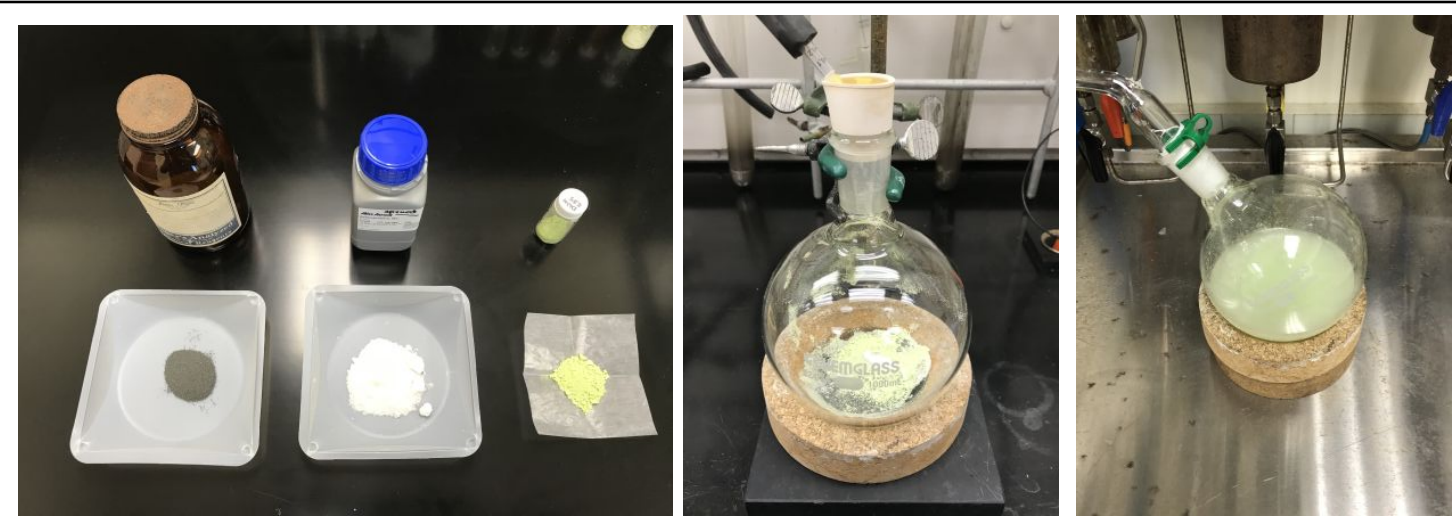

(Left) The $\mathrm{Zn}$ (left), diphenylacetylene (1a, center), and $\mathrm{Ni}\left(\right.$ phen) $\mathrm{Cl}_{2}$ (right) can all be weighed out open to air with no special precautions taken. (Center) The (24/40) 1 L round bottom flask is shown before the addition of solvent or any liquid reagents. (Right) The solvent (600 mL DMF) is added on an inert-atmosphere solvent system.

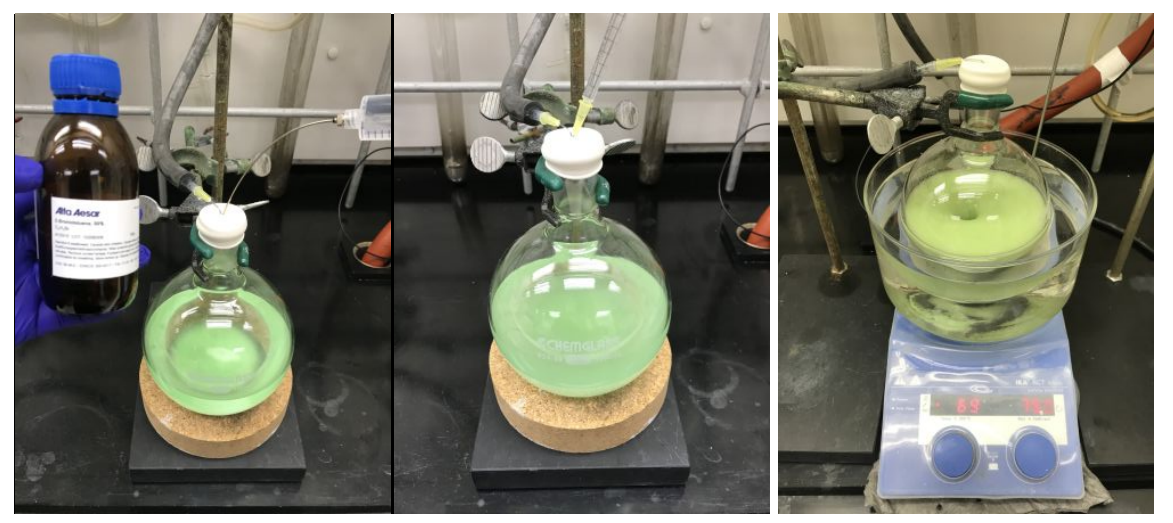

(Left) The ortho-bromotoluene (2a) is added under $\mathrm{N}_{2}$ via syringe. (Center) The deionized $\mathrm{H}_{2} \mathrm{O}$ is added under $\mathrm{N}_{2}$ via syringe. (Right) The reaction is stirred at $70{ }^{\circ} \mathrm{C}$ for 28 hours. For the first hour the reaction retains the (light green) color of the $\mathrm{Ni}(\mathrm{phen}) \mathrm{Cl}_{2}$ precatalyst.
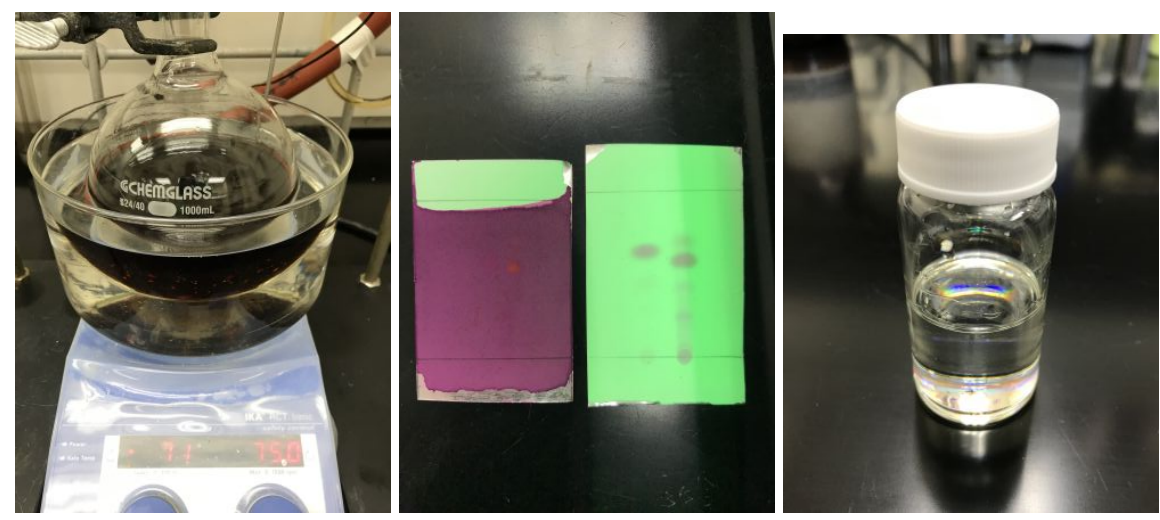

(Left) After stirring at $70{ }^{\circ} \mathrm{C}$ for about 1 hour the reaction turns the characteristic (deep red) color of the $\mathrm{Ni}$ (II) aryl halide intermediate. (Center) TLC analysis of the reaction material (right lane) compared to the diphenylacetylene starting material (left lane) shows the reaction was complete after 28 hours (left TLC plate is $\mathrm{KMnO}_{4}$ stain). (Right) Quenching with sat. aq. $\mathrm{NH}_{4} \mathrm{Cl}$, filtering, extraction with diethyl ether, and column chromatography on silica gel provided the product (3a, $10.9 \mathrm{~g}, 72 \%$ ) as a clear oil. 
A noticeable effect on the reaction was observed based on the type and source of $\mathrm{Zn}$ use.

\begin{tabular}{|c|c|c|c|c|}
\hline $\mathrm{Ph}=$ & $\begin{array}{l}\equiv \mathrm{Ph} \\
\mathbf{a}\end{array}$ & $2 a$ & $\begin{array}{c}\begin{array}{c}{\left[\mathrm{Ni}(\text { phen }) \mathrm{Cl}_{2}\right]} \\
(20 \text { mol } \%)\end{array} \\
\underset{\mathrm{Zn}(4.0 \text { equiv. })}{\mathrm{Zn}} \\
\mathrm{H}_{2} \mathrm{O}\left(\begin{array}{c}1.0 \text { equiv. }) \\
\text { DMF }\end{array}\right.\end{array}$ & $3 a$ \\
\hline entry & \multicolumn{3}{|c|}{ Zn Source } & $\%$ yield $3 a^{a}$ \\
\hline 1 & \multicolumn{3}{|c|}{ Granular Zn, 40 mesh, Baker Analyzed, Activated } & $73 \%$ \\
\hline 2 & \multicolumn{3}{|c|}{$\begin{array}{c}\text { Granular Zn, } 40 \text { mesh, Baker Analyzed, } \\
\text { Unactivated }\end{array}$} & $75 \%$ \\
\hline 3 & \multicolumn{3}{|c|}{$\begin{array}{l}\text { Granular Zn, } 30 \text { mesh, Acros Organics } \\
\text { (Catalog \# 222611000), Unactivated }\end{array}$} & $58 \%$ \\
\hline 4 & \multicolumn{3}{|c|}{$\begin{array}{l}\text { Granular Zn, } 20 \text { mesh, Acros Organics } \\
\text { (Catalog \# 222601000), Unactivated }\end{array}$} & $70 \%$ \\
\hline 5 & \multicolumn{3}{|c|}{$\begin{array}{l}\text { Powder Zn, } 20 \text { mesh, Fluka } \\
\text { (Catalog \# 96454), Unactivated }\end{array}$} & $21 \%$ \\
\hline 6 & \multicolumn{3}{|c|}{$\begin{array}{c}\text { Zn Flake, -325 mesh, 99.9\% Alfa Aesar } \\
\text { (Catalog \#13789), Activated }\end{array}$} & $8 \%$ \\
\hline
\end{tabular}

${ }^{a}$ Reactions were all prepared and analyzed using the General Procedure A for Reaction Optimization and GCMS Analysis. The yields reported were calculated by GC-MS against internal standard (corrected for relative response factors). Older samples of $\mathrm{Zn}$ could react more slowly, but generally gave good results in terms of chemical yield. The procedure for activating $\mathrm{Zn}$ was adopted from the report by Weix and coworkers. ${ }^{1}$ Activation of $\mathrm{Zn}$ refers to stirring $12 \mathrm{~g}$ of $\mathrm{Zn}$ in $30 \mathrm{~mL}$ aqueous $\mathrm{HCl}(2 \% \mathrm{v}: \mathrm{v})$ for 1 minute and then washing with deionized $\mathrm{H}_{2} \mathrm{O}$. Activated $\mathrm{Zn}$ samples were subsequently washed with ethanol and diethyl ether, and then dried overnight at $150{ }^{\circ} \mathrm{C}$. Similar to the results reported by Weix, $\mathrm{Zn}$ which was exposed to aqueous $\mathrm{HCl}$ for extended periods of time was too activated. High surface area (smaller mesh size) Zn samples also gave lower chemical yields. Reactions with $\mathrm{Zn}$ samples which were too activated frequently produced higher quantities of hydrodehalogenation byproducts (in this case toluene). These observations are consistent with those reported by the Weix group related to several reductive cross-coupling reactions catalyzed by $\mathrm{Ni} .1,2$ 
VI. Table S2. Aryl Bromides Used Throughout the Hydroarylation Study<smiles>Cc1ccccc1Br</smiles>

$2 a$<smiles>Clc1ccc(Br)cc1</smiles>

$2 e$<smiles>Cc1ccc(Br)c(C)c1</smiles>

2i<smiles>Brc1cccc2ccccc12</smiles>

$2 \mathrm{~m}$<smiles>Cc1cc(C)c(Br)c(C)c1</smiles>

$(<5 \%)$<smiles>Brc1ccccc1</smiles>

$2 b$<smiles>Fc1ccc(Br)cc1</smiles>

$2 f$<smiles>Cc1ccc(C)c(Br)c1</smiles>

2j<smiles>Cc1cccc(Br)c1</smiles>

$2 n$<smiles>O=[N+]([O-])c1cccc(Br)c1</smiles>

(unreactive)<smiles>Cc1ccc(Br)cc1</smiles>

2c<smiles>FC(F)(F)c1ccc(Br)cc1</smiles>

$2 g$<smiles>Cc1cccc(Br)c1C</smiles>

2k<smiles>CCc1cccc(Br)c1</smiles>

20<smiles>Clc1cccc(Br)c1</smiles>

(inseparable byproducts)<smiles>COc1ccc(Br)cc1</smiles>

2d<smiles>COC(=O)c1ccc(Br)cc1</smiles>

2h<smiles>CCc1ccccc1Br</smiles>

2I<smiles>CC(C)(C)c1cc(Br)cc(C(C)(C)C)c1</smiles>

$2 p$ 
VII. Table S3. Effects of Precatalyst Loading (NMR Yields and Z/E Ratios for Selected Aryl Bromide Substrates)<smiles>C(=C/c1ccccc1)\c1ccccc1</smiles>

3 b $65 \%$ $20 \% \mathrm{Ni}($ phen $) \mathrm{Cl}_{2}$ :

$71 \%$ by NMR $10 \% \mathrm{Ni}$ (phen) $\mathrm{Cl}_{2}$ :

$57 \%$ by NMR<smiles>Cc1ccc(/C(=C\c2ccccc2)c2ccccc2)c(C)c1</smiles>

$3 \mathbf{i} 61 \%$ (7.0:1 ZIE) $20 \% \mathrm{Ni}$ (phen) $\mathrm{Cl}_{2}$ : $71 \%$ by NMR $(6.7: 1$ ZIE)<smiles>CCc1ccccc1/C(=C\c1ccccc1)c1ccccc1</smiles>

$3157 \%$

(6.3:1 Z/E) $20 \% \mathrm{Ni}($ phen $) \mathrm{Cl}_{2}$ : $53 \%$ by NMR (4.7:1 ZIE) $10 \% \mathrm{Ni}($ phen $) \mathrm{Cl}_{2}$ : $48 \%$ by NMR (4.7:1 Z/E)<smiles>CC(C)(C)c1cc(C(=Cc2ccccc2)c2ccccc2)cc(C(C)(C)C)c1</smiles>

3p $53 \%$

(1.4:1 Z/E)

$20 \% \mathrm{Ni}\left(\right.$ phen) $\mathrm{Cl}_{2}$ : $78 \%$ by NMR (1.3:1 ZIE)<smiles>Cc1ccc(C(=Cc2ccccc2)c2ccccc2)cc1</smiles>

3c $54 \%$

$(1: 1 \mathrm{ZIE})$

$20 \% \mathrm{Ni}\left(\right.$ phen) $\mathrm{Cl}_{2}$ : $60 \%$ by NMR (1:1 Z/E) $10 \% \mathrm{Ni}\left(\right.$ phen $\mathrm{Cl}_{2}$ : $48 \%$ by NMR (1:1 Z/E)<smiles>Cc1ccc(C)c(/C(=C\c2ccccc2)c2ccccc2)c1</smiles>

3j $72 \%$

(4.1:1 Z/E)

$20 \% \mathrm{Ni}$ (phen) $\mathrm{Cl}_{2}$ :

$66 \%$ by NMR (3.5:1 ZIE)

$10 \% \mathrm{Ni}($ phen $) \mathrm{Cl}_{2}$ :

$74 \%$ by NMR (3.3:1 ZIE)<smiles>Cc1cccc(/C(=C\c2ccccc2)c2ccccc2)c1</smiles>

3n $61 \%$

(1.2:1 Z/E) $20 \% \mathrm{Ni}($ phen $) \mathrm{Cl}_{2}$ : $54 \%$ by NMR (1.2:1 ZIE) $10 \% \mathrm{Ni}$ (phen) $\mathrm{Cl}_{2}$ : $63 \%$ by NMR (1.2:1 Z/E)<smiles>COc1ccc(C(=Cc2ccccc2)c2ccccc2)cc1</smiles>

3d $60 \%$

$(1: 1 \mathrm{ZIE})$

$20 \% \mathrm{Ni}$ (phen) $\mathrm{Cl}_{2}$ : $66 \%$ by NMR $(1: 1$ ZIE)<smiles>Cc1cccc(/C(=C\c2ccccc2)c2ccccc2)c1C</smiles>

3k $60 \%$ (5.0:1 Z/E) $20 \% \mathrm{Ni}$ (phen) $\mathrm{Cl}_{2}$ : $64 \%$ by NMR (5.0:1 Z/E)<smiles>CCc1cccc(C(=Cc2ccccc2)c2ccccc2)c1</smiles>

$3055 \%$

$(1: 1 \mathrm{ZIE})$

$20 \% \mathrm{Ni}($ phen $) \mathrm{Cl}_{2}$ : $63 \%$ by NMR (1:1 Z/E) 
VIII. Figure S5. Assignment of the stereochemistry for 3k and $\mathbf{3 1 .}$

Neither the compound $\mathbf{3 k}$ nor $\mathbf{3} \mathbf{l}$ have been previously reported. The stereochemistry of the major isomer was assigned as $(Z)$ in both cases based on comparisons with the other compounds reported in this study. NOESY NMR analysis was inconclusive for both compounds. For compound 3k, both alkene isomers showed weak NOE signals between the alkene hydrogen and a methyl group. For compound 31, both alkene isomers showed weak NOE signals between the alkene hydrogen and the methylene group. Nevertheless, analysis of the other previously reported substrates with ortho methyl groups (3a, 3i, and $\mathbf{3 j}$ ) indicates that they all demonstrate reliable chemical shift differences for the $(Z)$ and $(E)$ isomers. The alkene hydrogen for the $(Z)$ isomer is nearly always located at $7.10 \mathrm{ppm}$, or slightly higher (see below). The resonance for the $(Z)$ isomer alkene hydrogen can overlap with other signals, but the resonance for the $(E)$ isomer alkene hydrogen is always well resolved and located around 6.606.70 ppm (see below).

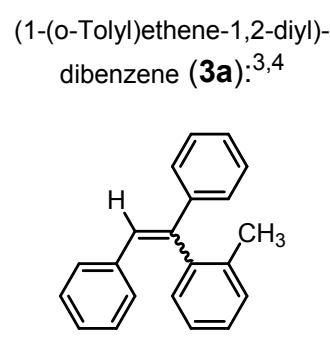

Alkene Hydrogen Resonance

(Z) Isomer $=7.09 \mathrm{ppm}$

$(E)$ Isomer $=6.63 \mathrm{ppm}$
(1-(2,4-Dimethylphenyl)ethene-1,2-diyl)dibenzene $(3 i):^{5}$

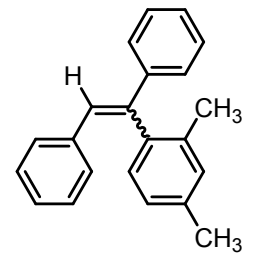

Alkene Hydrogen Resonance

(Z) Isomer $=7.10 \mathrm{ppm}$

$(E)$ Isomer $=6.65 \mathrm{ppm}$
(1-(2,5-Dimethylphenyl)ethene-1,2-diyl)dibenzene $(\mathbf{3} \mathbf{j}): 6,7,8$

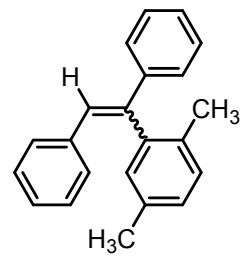

Alkene Hydrogen Resonance

(Z) Isomer $=7.14 \mathrm{ppm}$

(E) Isomer $=6.70 \mathrm{ppm}$
(1-(2,3-Dimethylphenyl)ethene-1,2-diyl)dibenzene (3k):

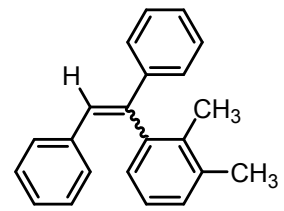

Alkene Hydrogen Resonance

Major Isomer $=7.11 \mathrm{ppm}$

Minor Isomer $=6.63 \mathrm{ppm}$
(1-(2-Ethylphenyl)ethene-1,2-diyl)dibenzene (3I):

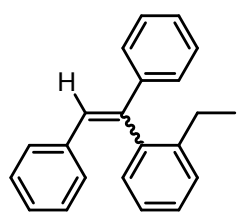

Alkene Hydrogen Resonance

Major Isomer $=7.12 \mathrm{ppm}$

Minor Isomer $=6.67 \mathrm{ppm}$

To further substantiate these stereochemical assignments we subjected diphenylacetylene (1a) to the syn-selective hydroarylation conditions reported by Xue, Zhao, and Hor. ${ }^{9}$ As a control experiment, 1a was reacted with $o$ tolylmagnesium bromide and ligandless $\mathrm{NiCl}_{2} \cdot 6 \mathrm{H}_{2} \mathrm{O}$ as a precatalyst. Under these previously reported conditions the yield for 3a was fairly low, but the major isomer formed was the $(E)$ isomer expected from syn addition. 


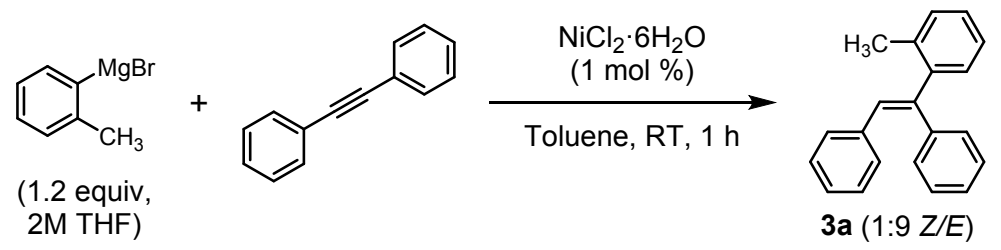

When 1a was reacted with (2-ethyphenyl)magnesium bromide under analogous conditions, the major isomer of 3 formed (bottom) was indeed the minor isomer formed under the conditions listed above for the title reaction.

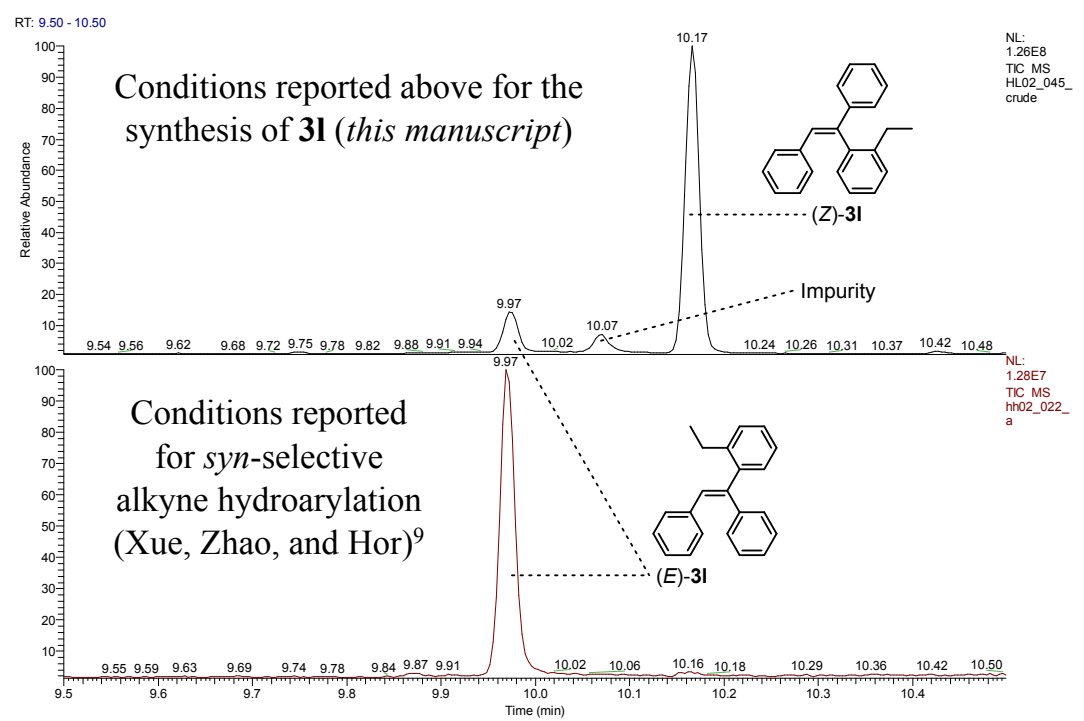


IX. Figure S6. Assignment of the stereochemistry for 3q:

Neither the compound $\mathbf{3 q}$ nor the $(E)$ isomer have been previously reported. The stereochemistry has been assigned as $(Z)$ based on comparisons with similar known compounds and NOESY NMR experiments. The benzylic methyl group and the trimethylsilyl group show a weak NOE signal, but this observation cannot be used to unequivocally prove the assignment. The chemical shift of the alkene proton is consistent with the $(Z)$ stereochemistry since alkene hydrogen atoms syn to an ortho-tolyl group tend to be shifted significantly upfield relative to those adjacent to less sterically hindered aryl groups.

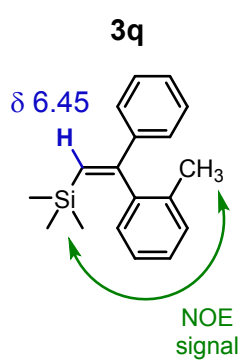

Ref 10 (J. Org. Chem. 2014, 79, 5799)
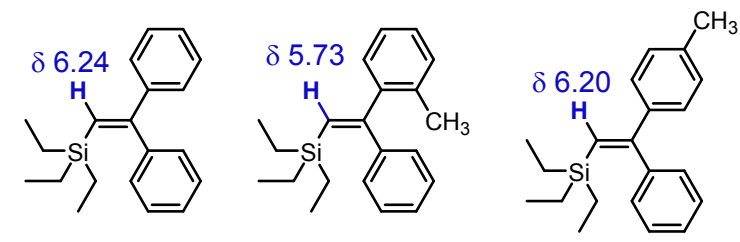

To further substantiate this stereochemical assignment the product 3q was treated with 1.0 equiv $\mathrm{N}$ bromosuccinimide in acetonitrile overnight to produce (Z)-1-(2-bromo-1-phenylvinyl)-2-methylbenzene as a single diastereomer $(>20: 1 Z: E)$. The synthesis of this known compound ${ }^{11}$ provides strong evidence that the stereochemical assignment of $(Z)$ for $\mathbf{3 q}$ is correct.
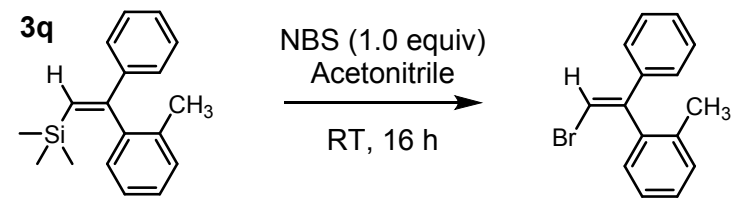

(Z)-1-(2-bromo-1-phenylvinyl)-2-methylbenzene

Ref 11 (Tetrahedron 2019, 75, 1658) 


\section{References}

(1) Everson, D. A.; Jones, B. A.; Weix, D. J. Replacing Conventional Carbon Nucleophiles with Electrophiles: Nickel-Catalyzed Reductive Alkylation of Aryl Bromides and Chlorides. J. Am. Chem. Soc. 2012, 134, 61466159.

(2) Everson, D. A.; George, D. T.; Weix, D. J. Nickel-Catalyzed Cross-Coupling of Aryl Halides with Alkyl Halides: Ethyl 4-(4-(4-methylphenylsulfonamido)-phenyl)butanoate. Org. Synth. 2013, 90, 200-214.

(3) Barluenga, J.; Florentino, L.; Aznar, F.; Valdés, C. Synthesis of Polysubstituted Olefins by Pd-Catalyzed Cross-Coupling Reaction of Tosylhydrazones and Aryl Nonaflates. Org. Lett. 2011, 13, 510-513.

(4) Wen, H.; Zhang, L.; Zhu, S.; Liu, G.; Huang, Z. Stereoselective Synthesis of Trisubstituted Alkenes via Cobalt-Catalyzed Double Dehydrogenative Borylations of 1-Alkenes. ACS Catal. 2017, 7, 6419-6429.

(5) Cacchi, S.; Fabrizi, G.; Goggiamani, A.; Persiani, D. Palladium-Catalyzed Hydroarylation of Alkynes with Arenediazonium Salts. Org. Lett. 2008, 10, 1597-1600.

(6) Song, C. E.; Jung, D.-u.; Choung, S. Y.; Roh, E. J.; Lee, S.-g. Dramatic Enhancement of Catalytic Activity in an Ionic Liquid: Highly Practical Friedel-Crafts Alkenylation of Arenes with Alkynes Catalyzed by Metal Triflates. Angew. Chem., Int. Ed. 2004, 43, 6183-6185.

(7) Choi, D. S.; Kim, J. H.; Shin, U. S.; Deshmukh, R. R.; Song, C. E. Thermodynamically- and kineticallycontrolled Friedel-Crafts alkenylation of arenes with alkynes using an acidic fluoroantimonate(V) ionic liquid as catalyst. Chem Commun. 2007, 3482-3484.

(8) Jones, R. C.; Gałęzowski, M.; O’Shea, D. F. Synthesis of Trisubstituted Alkenes via Direct Oxidative Arene-Alkene Coupling. J. Org. Chem. 2013, 78, 8044-8053.

(9) Xue, F.; Zhao, J.; Hor, T. S. A. Ambient arylmagnesiation of alkynes catalysed by ligandless nickel(II). Chem. Commun. 2013, 49, 10121-10123.

(10) Kong, W.; Che, C.; Wu, J.; Ma, L.; Zhu, G. Pd-Catalyzed Regio- and Stereoselective Addition of Boronic Acids to Silylacetylenes: A Stereodivergent Assembly of $\beta, \beta$-Disubstituted Alkenylsilanes and Alkenyl Halides. J. Org. Chem. 2014, 79, 5799-5805.

(11) Zhang, G.; Bai, R.-X.; Li, C.-H.; Feng, C.-G.; Lin, G.-Q. Halogenation of 1,1-diarylethylenes by $N$ halosuccinimides. Tetrahedron 2019, 75, 1658-1662. 
${ }^{1}$ H NMR Spectrum for (Z)-(1-(o-tolyl)ethene-1,2-diyl)dibenzene (3a):

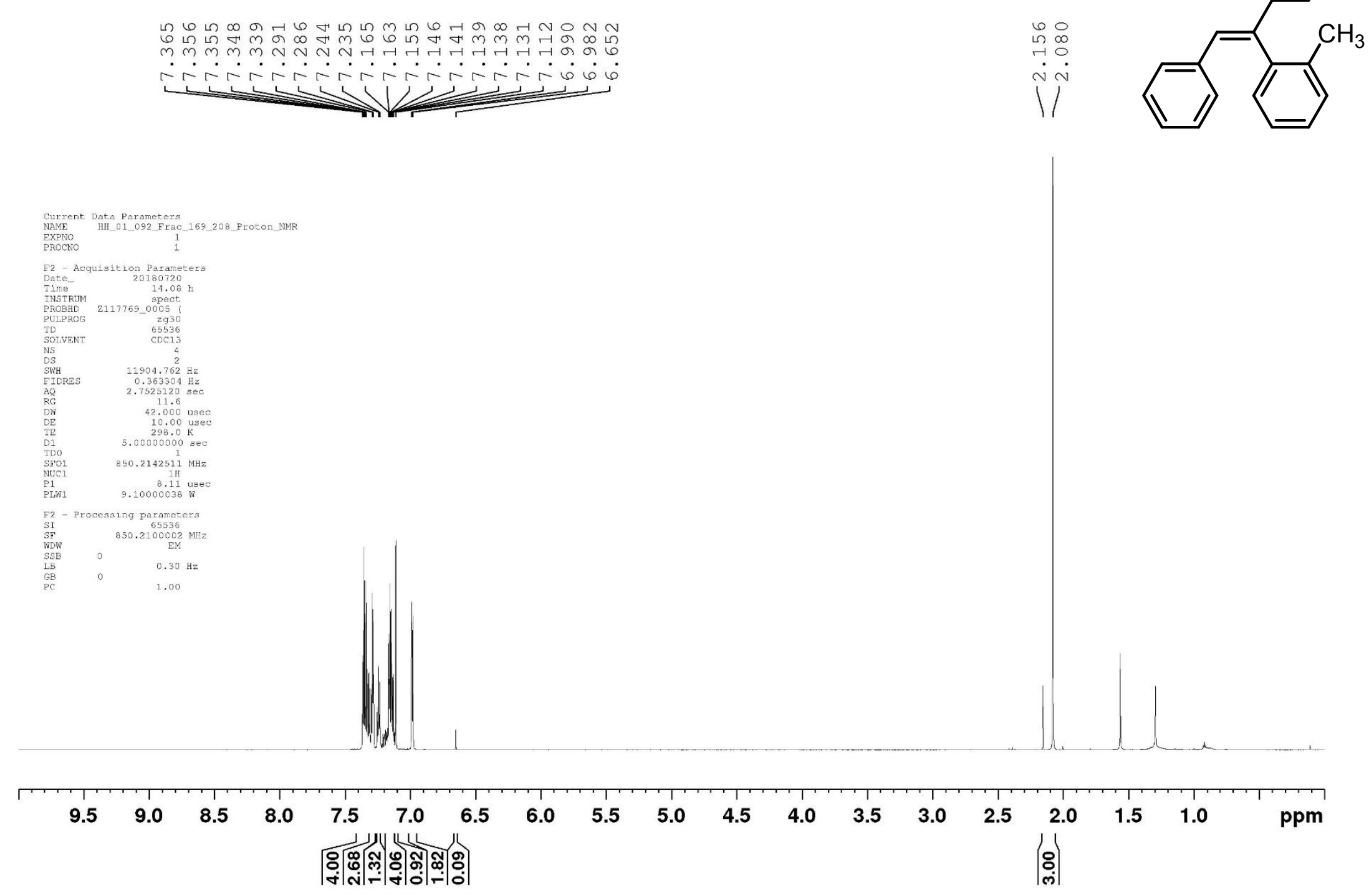


${ }^{13}$ C NMR Spectrum for ( $Z$ )-(1-(o-tolyl)ethene-1,2-diyl)dibenzene (3a):

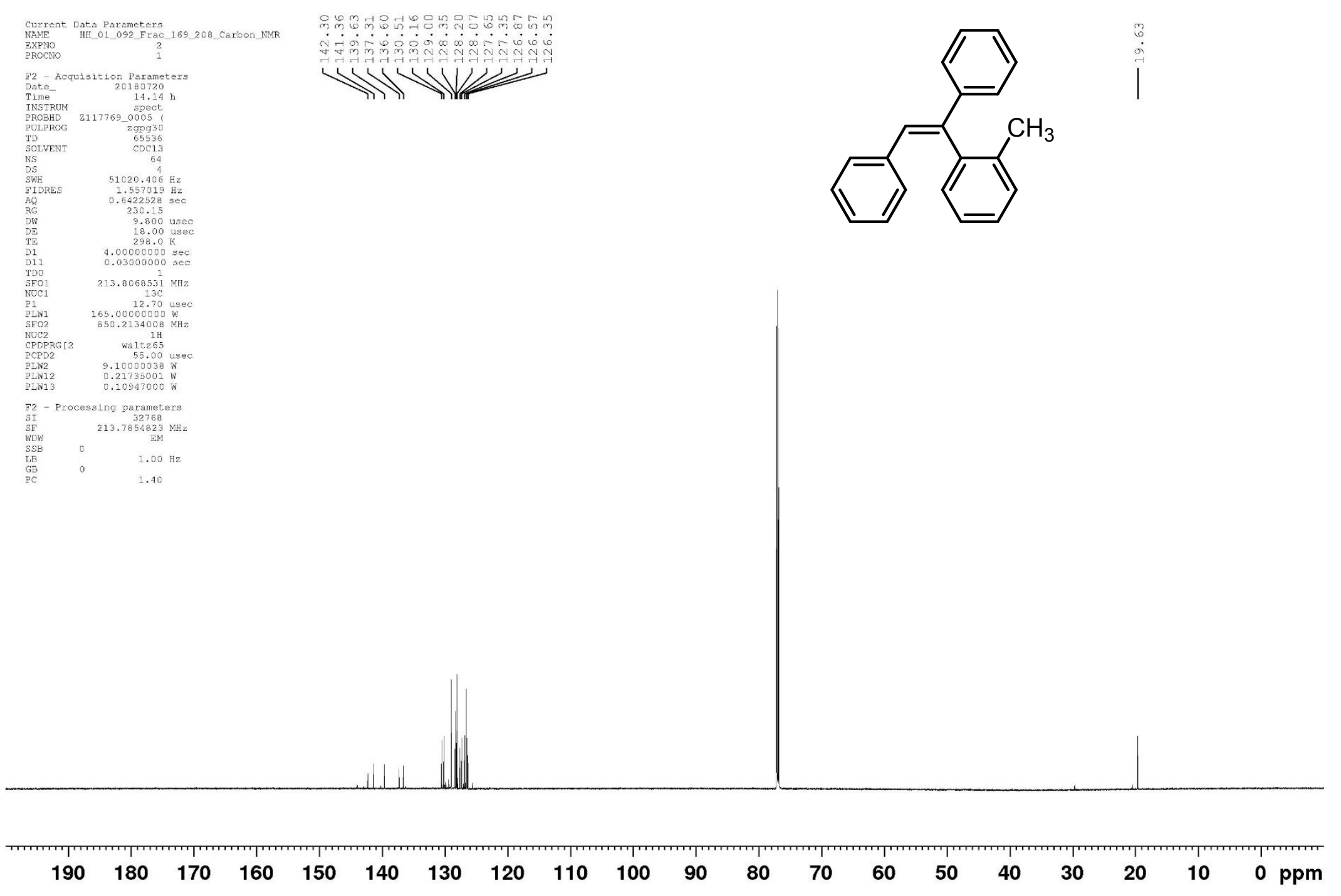


${ }^{1} \mathrm{H}$ NMR Spectrum for ethene-1,1,2-triyltribenzene (3b):

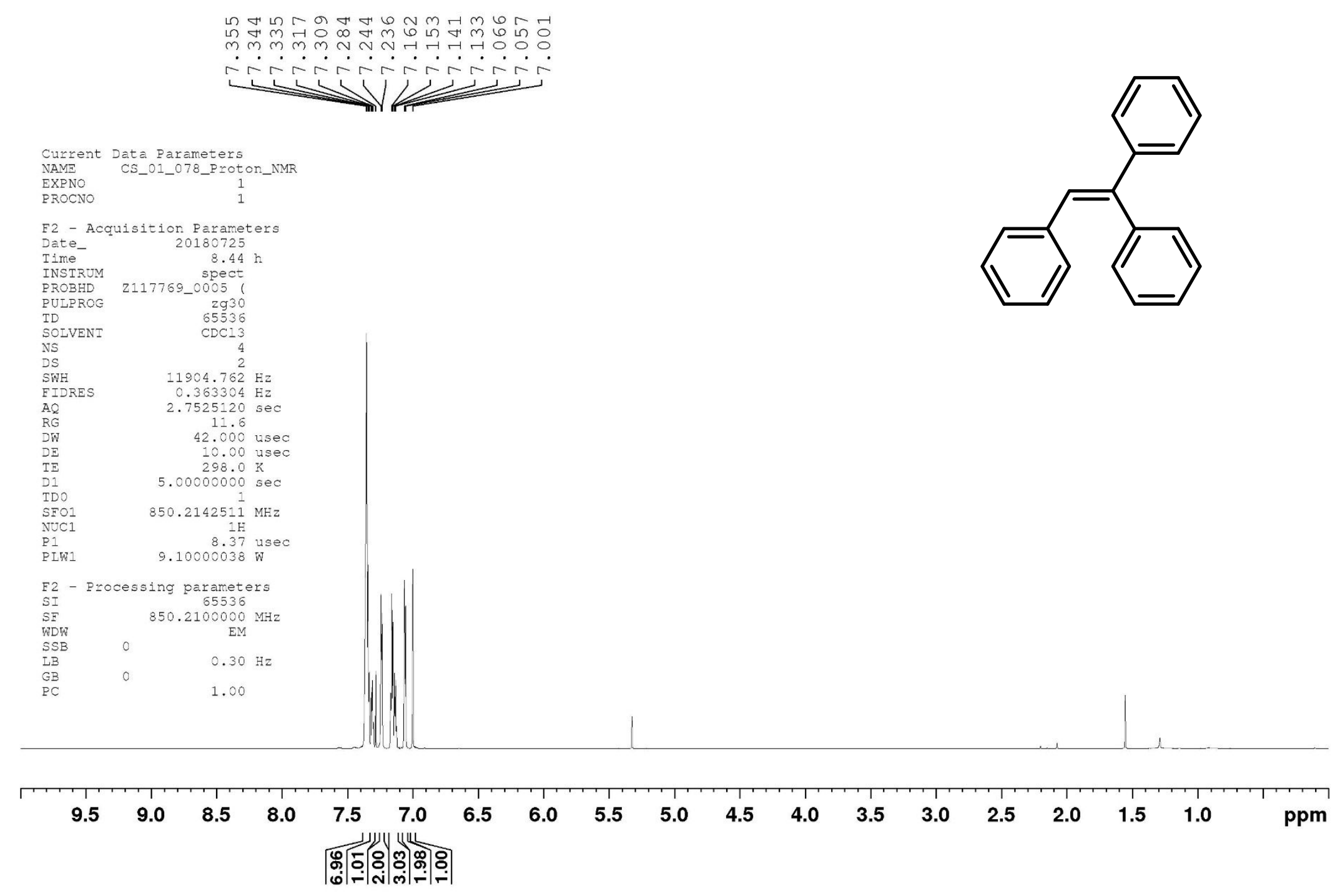


${ }^{13}$ C NMR Spectrum for ethene-1,1,2-triyltribenzene (3b):
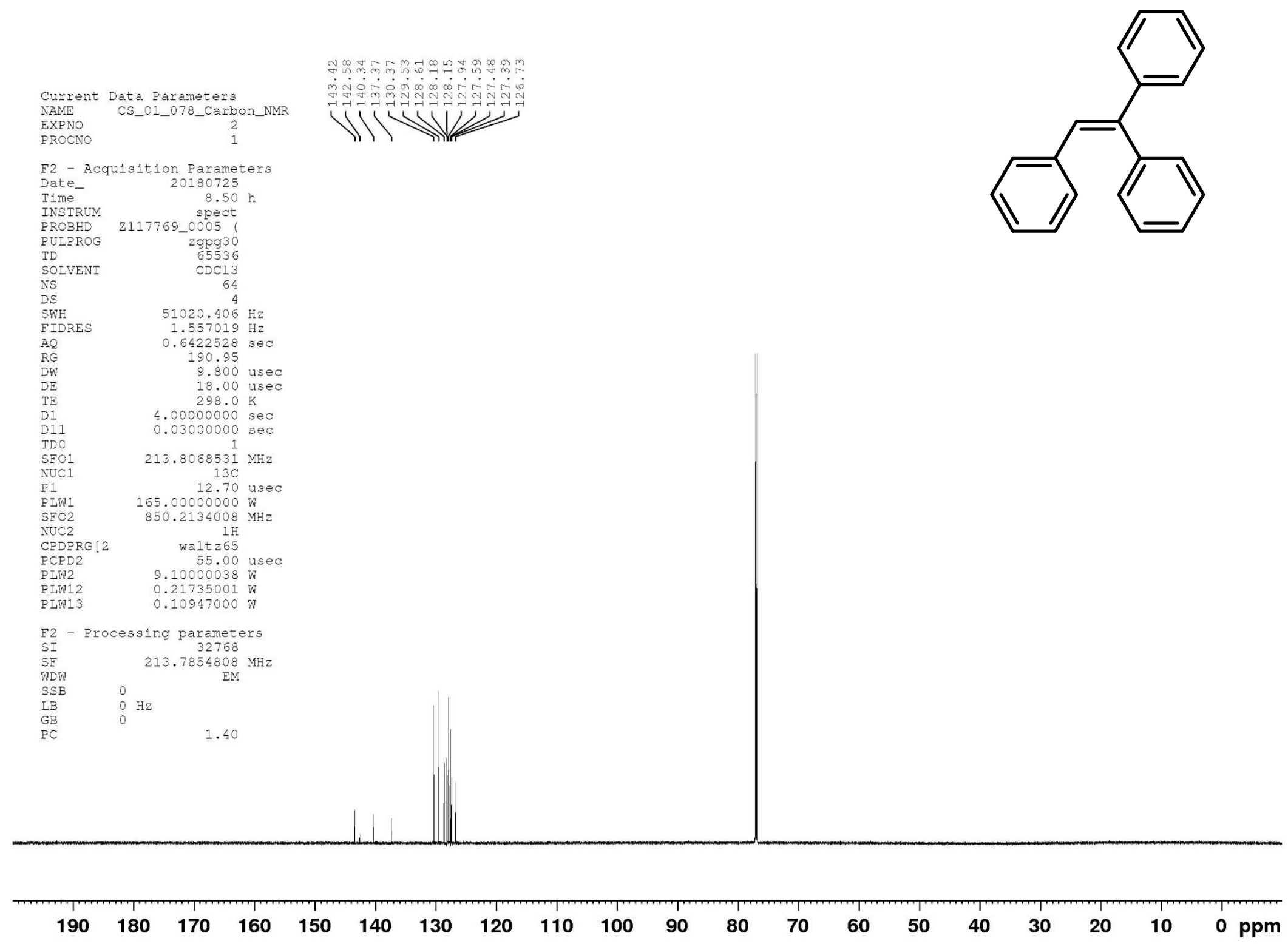
${ }^{1}$ H NMR Spectrum for (Z/E)-(1-(p-tolyl)ethene-1,2-diyl)dibenzene (3c):

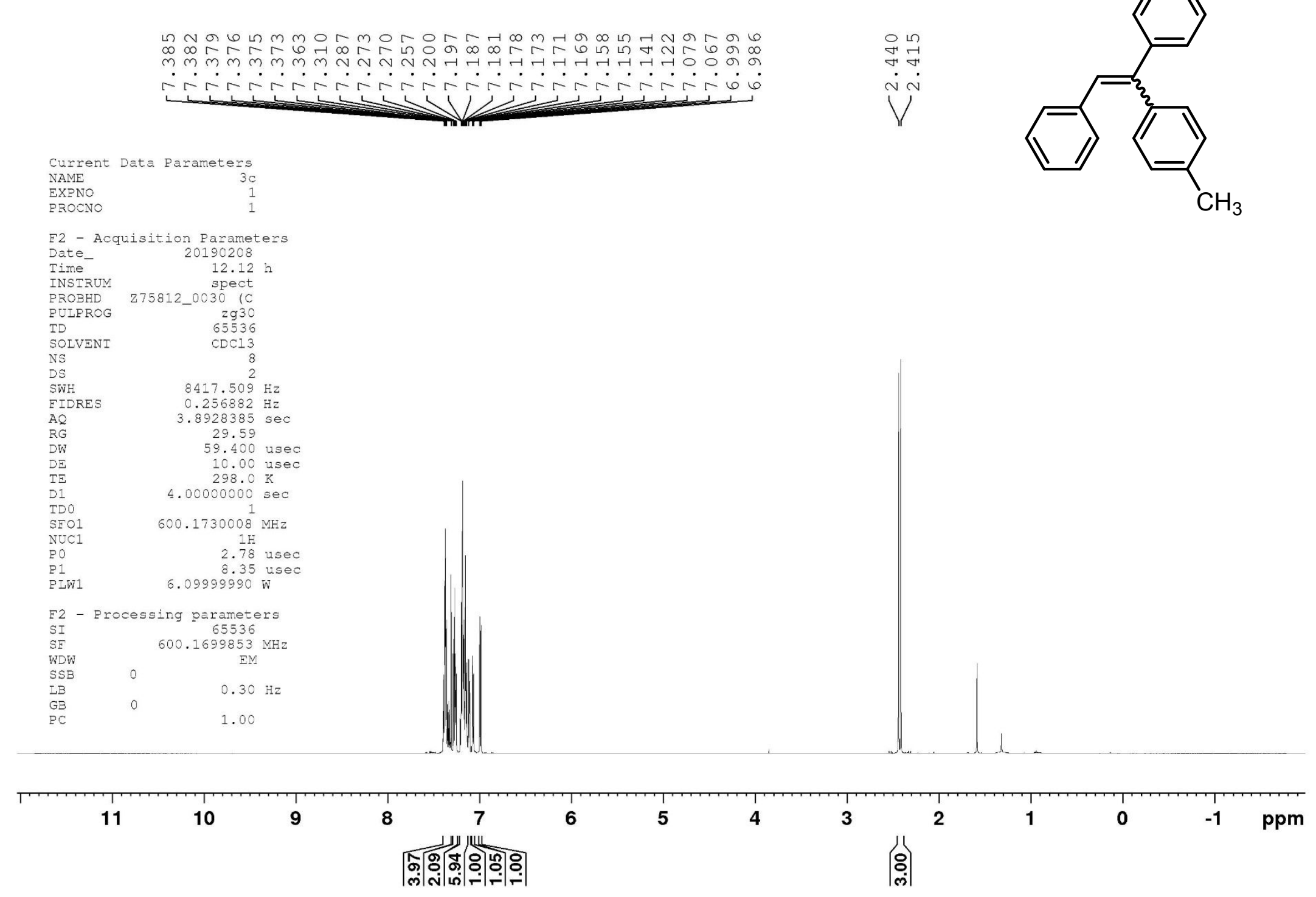


${ }^{13}$ C NMR Spectrum for (Z/E)-(1-(p-tolyl)ethene-1,2-diyl)dibenzene (3c):

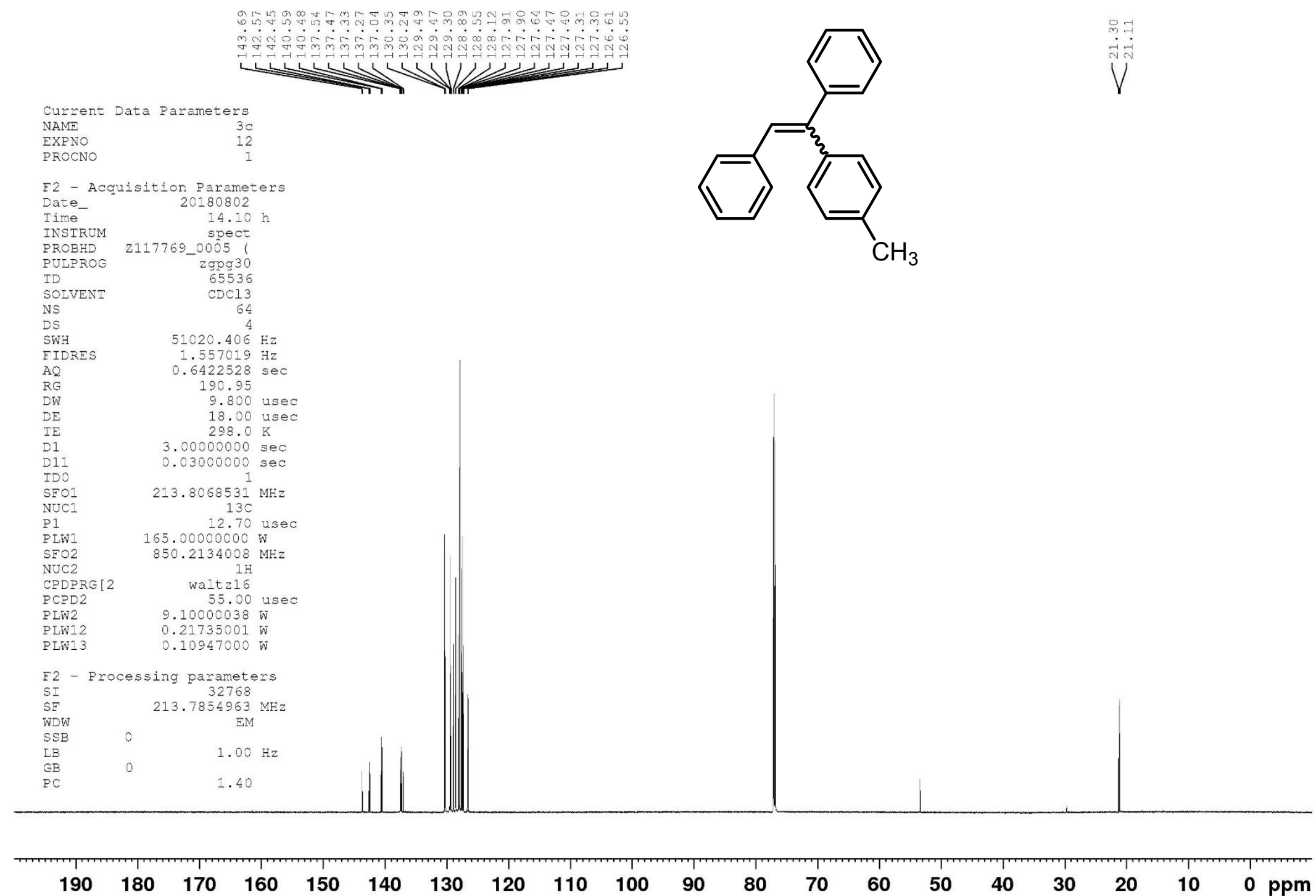


${ }^{1}$ H NMR Spectrum for (Z/E)-(1-(4-methoxyphenyl)ethene-1,2-diyl)dibenzene (3d):

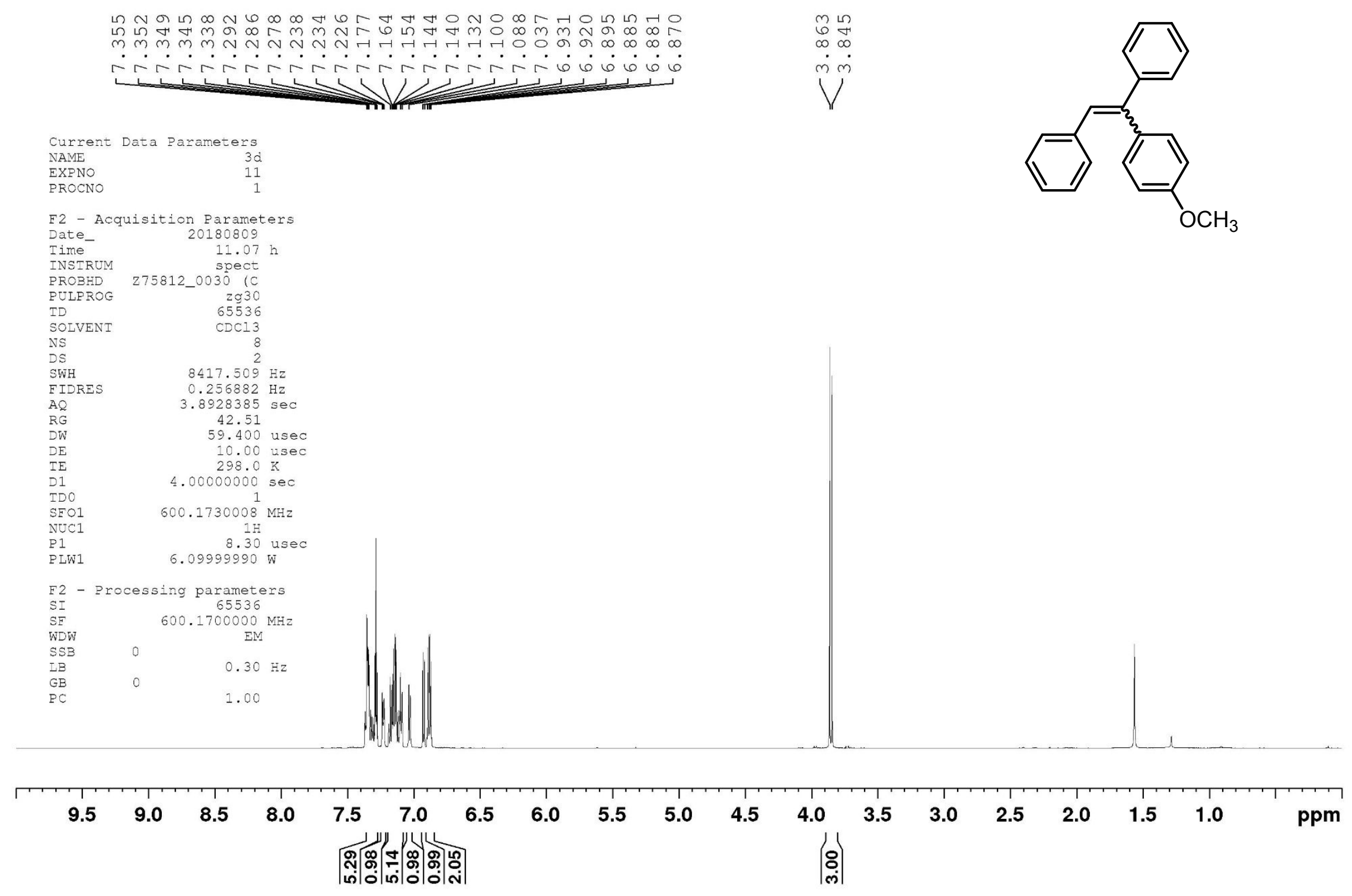


${ }^{13}$ C NMR Spectrum for (Z/E)-(1-(4-methoxyphenyl)ethene-1,2-diyl)dibenzene (3d):

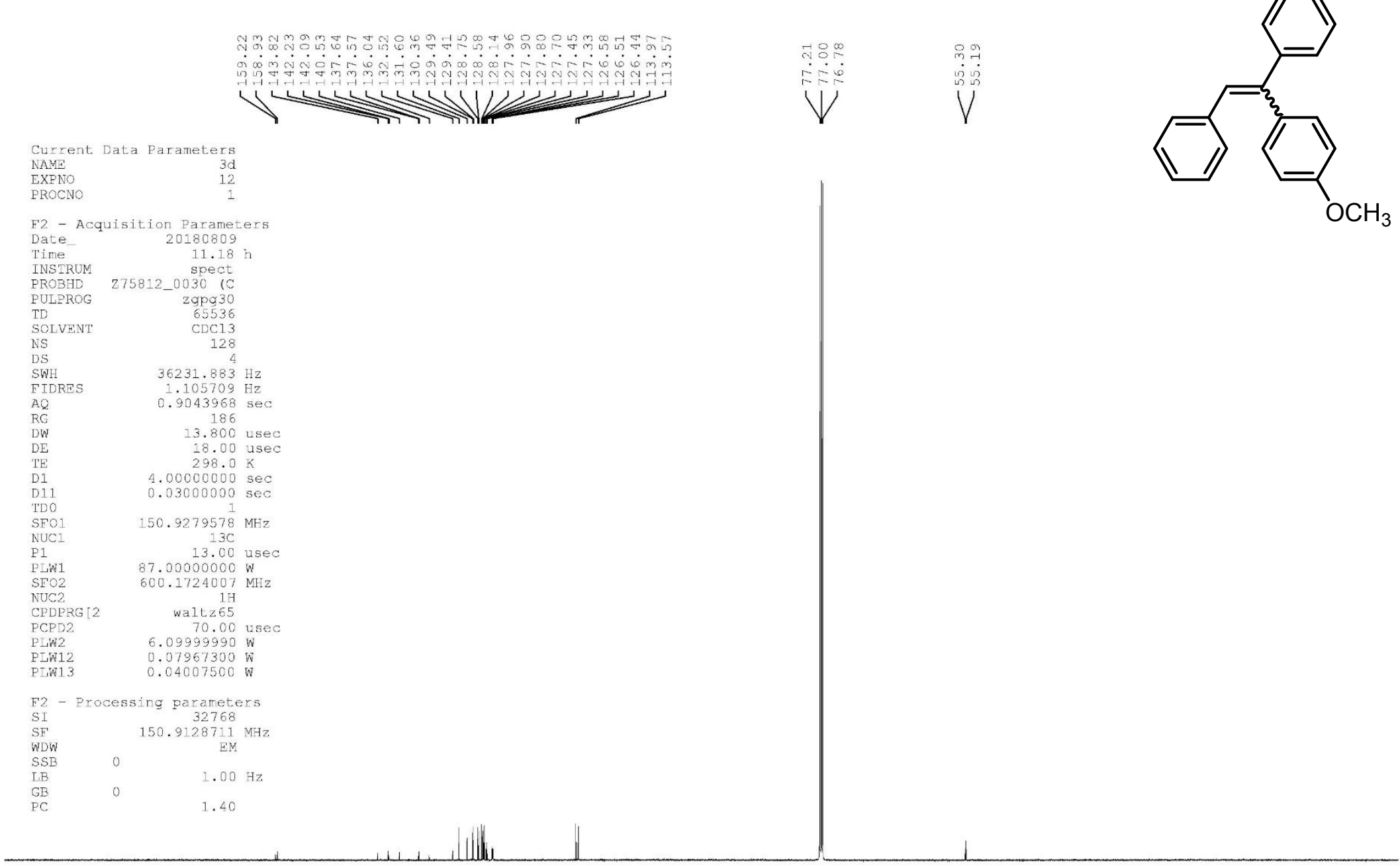

$\begin{array}{llllll}150 & 140 & 130 & 120 & 110 & 100\end{array}$

90

80

60

50

40

30

20

10

0 ppm 
${ }^{1}$ H NMR Spectrum for (Z/E)-(1-(4-chlorophenyl)ethene-1,2-diyl)dibenzene (3e):

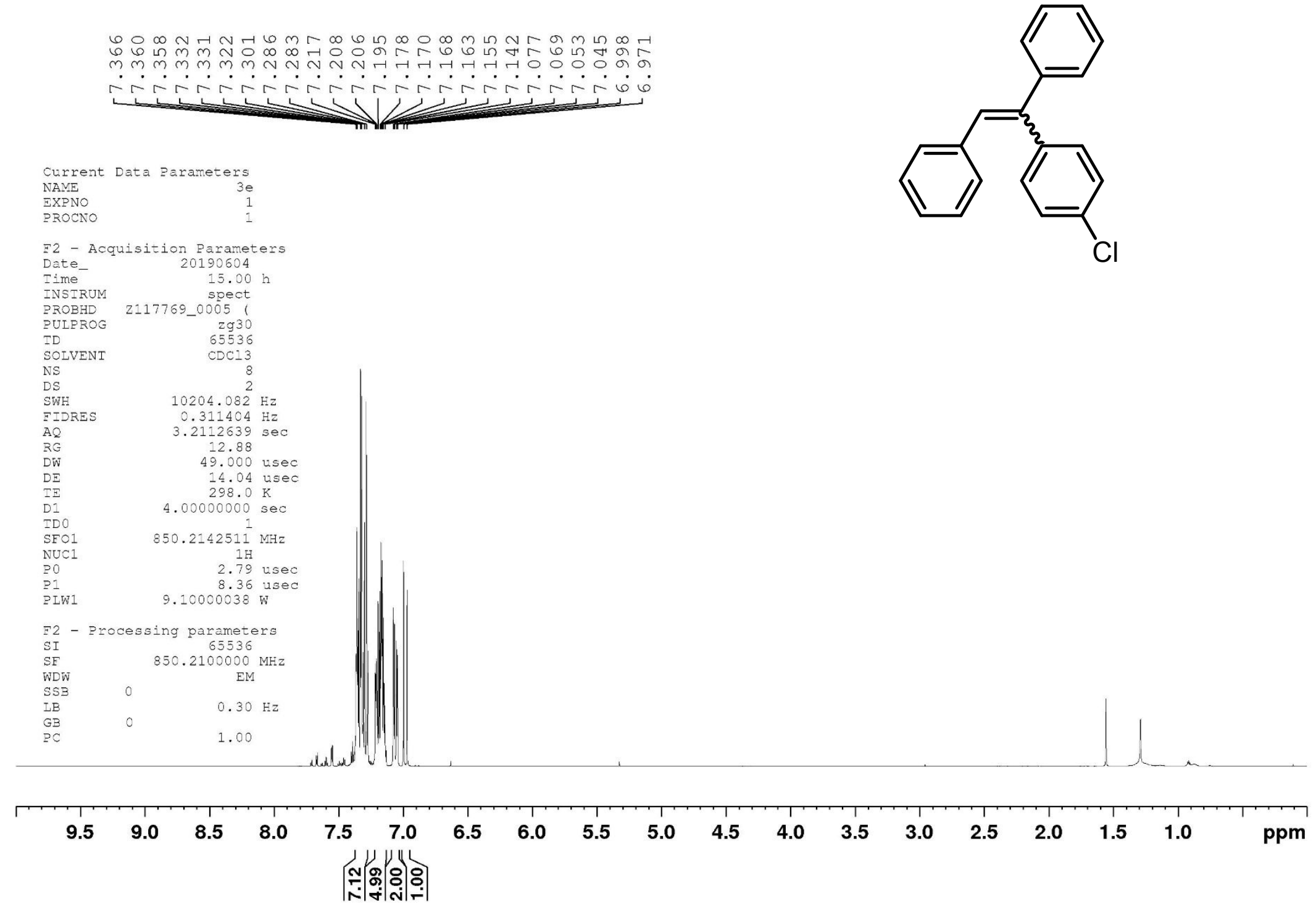


${ }^{13}$ C NMR Spectrum for (Z/E)-(1-(4-chlorophenyl)ethene-1,2-diyl)dibenzene (3e):

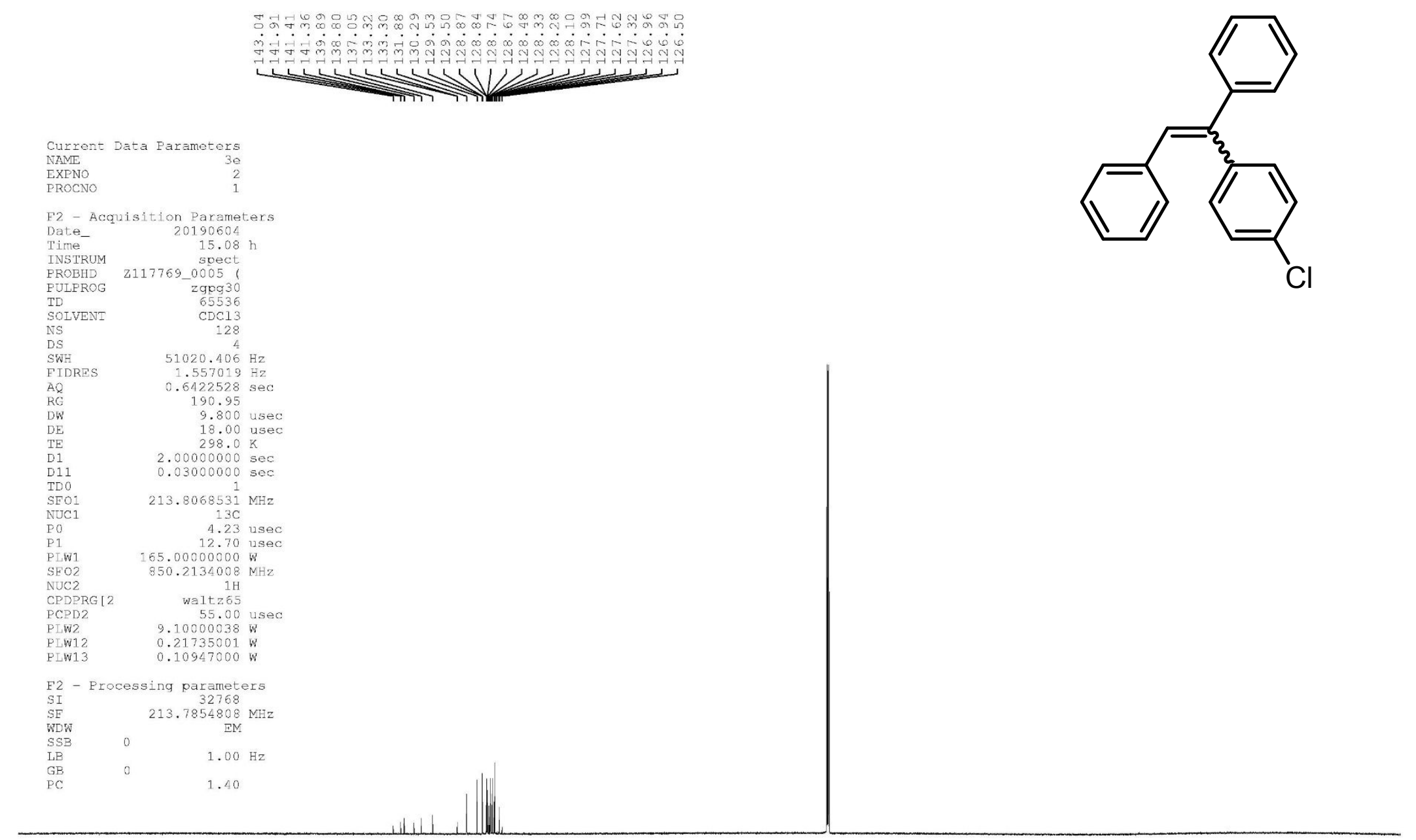

170

160

150

130

120

110100

90

80

70

60

0 ppm 
${ }^{1}$ H NMR Spectrum for (Z/E)-(1-(4-fluorophenyl)ethene-1,2-diyl)dibenzene (3f):

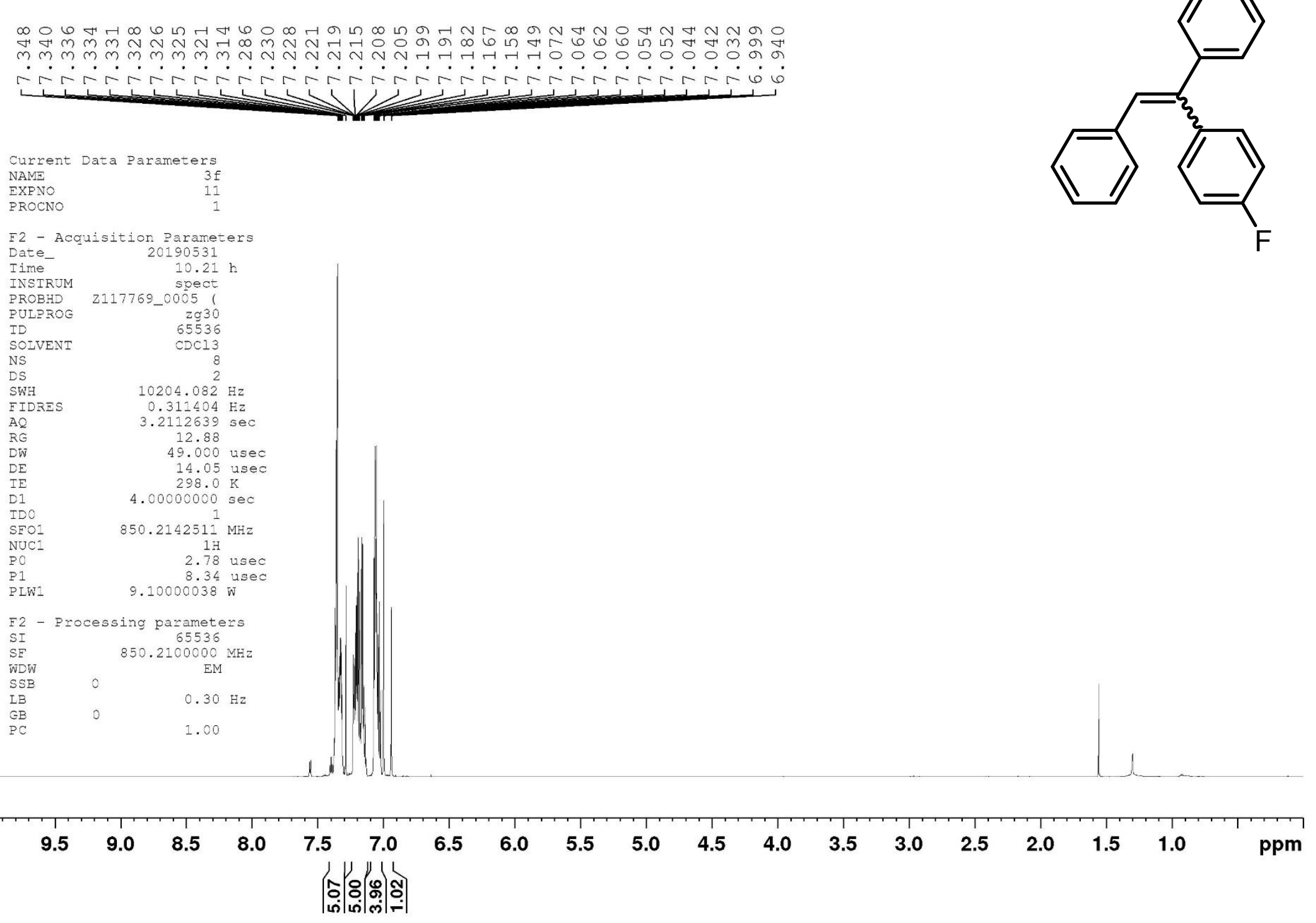


${ }^{13}$ C NMR Spectrum for (Z/E)-(1-(4-fluorophenyl)ethene-1,2-diyl)dibenzene (3f):

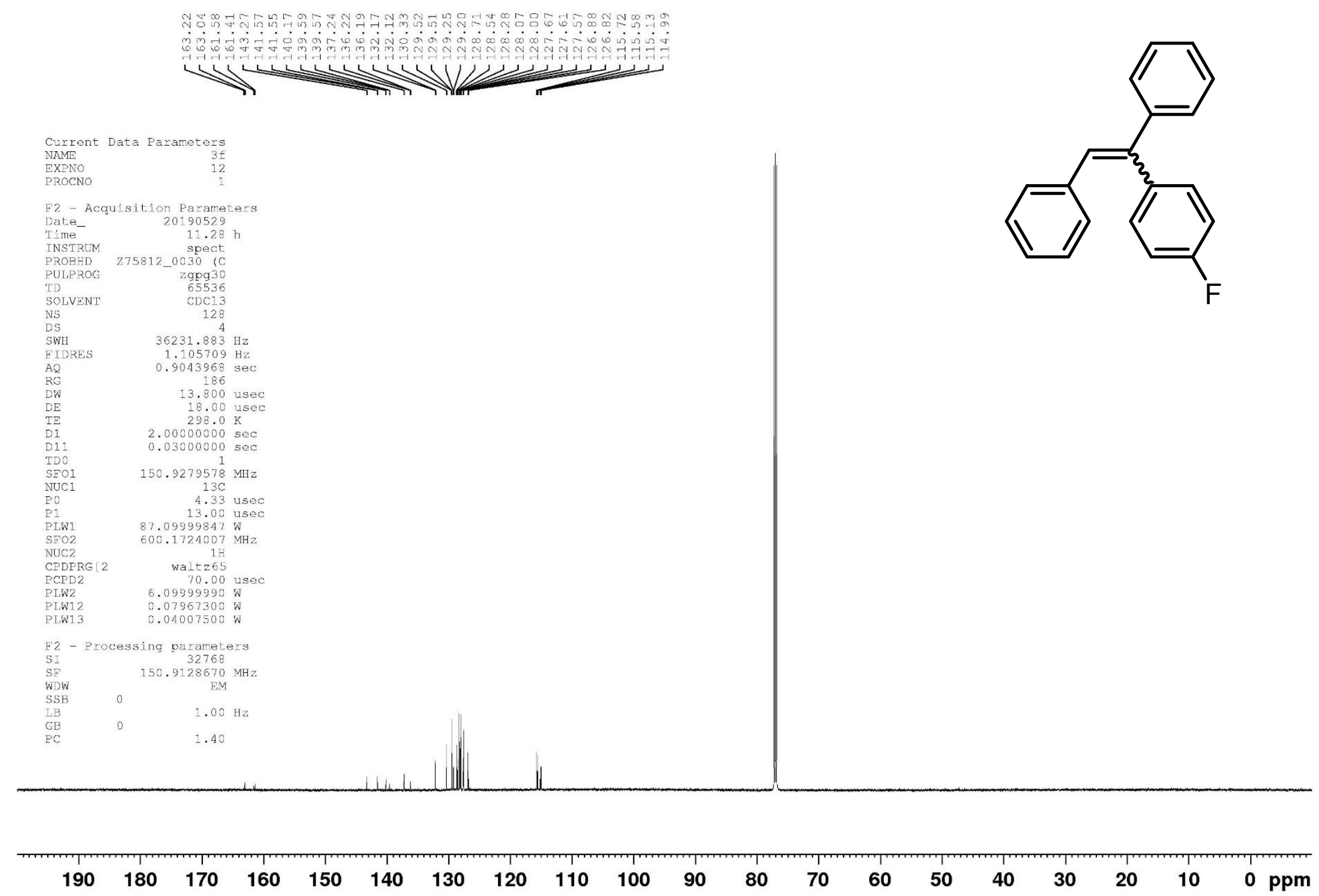


${ }^{1}$ H NMR Spectrum for (Z/E)-(1-(4-(trifluoromethyl)phenyl)ethene-1,2-diyl)dibenzene (3g):

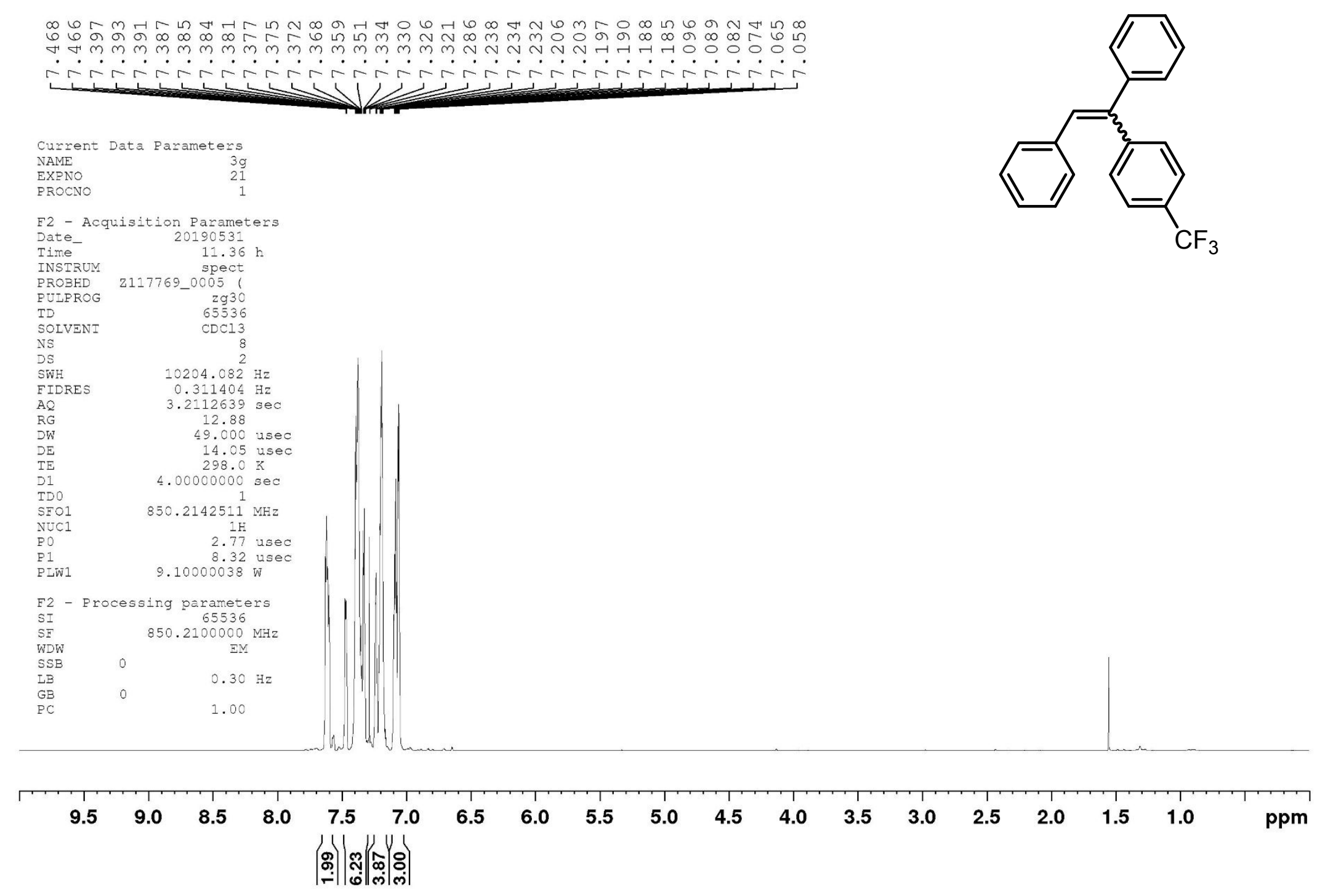


${ }^{13}$ C NMR Spectrum for (Z/E)-(1-(4-(trifluoromethyl)phenyl)ethene-1,2-diyl)dibenzene (3g):

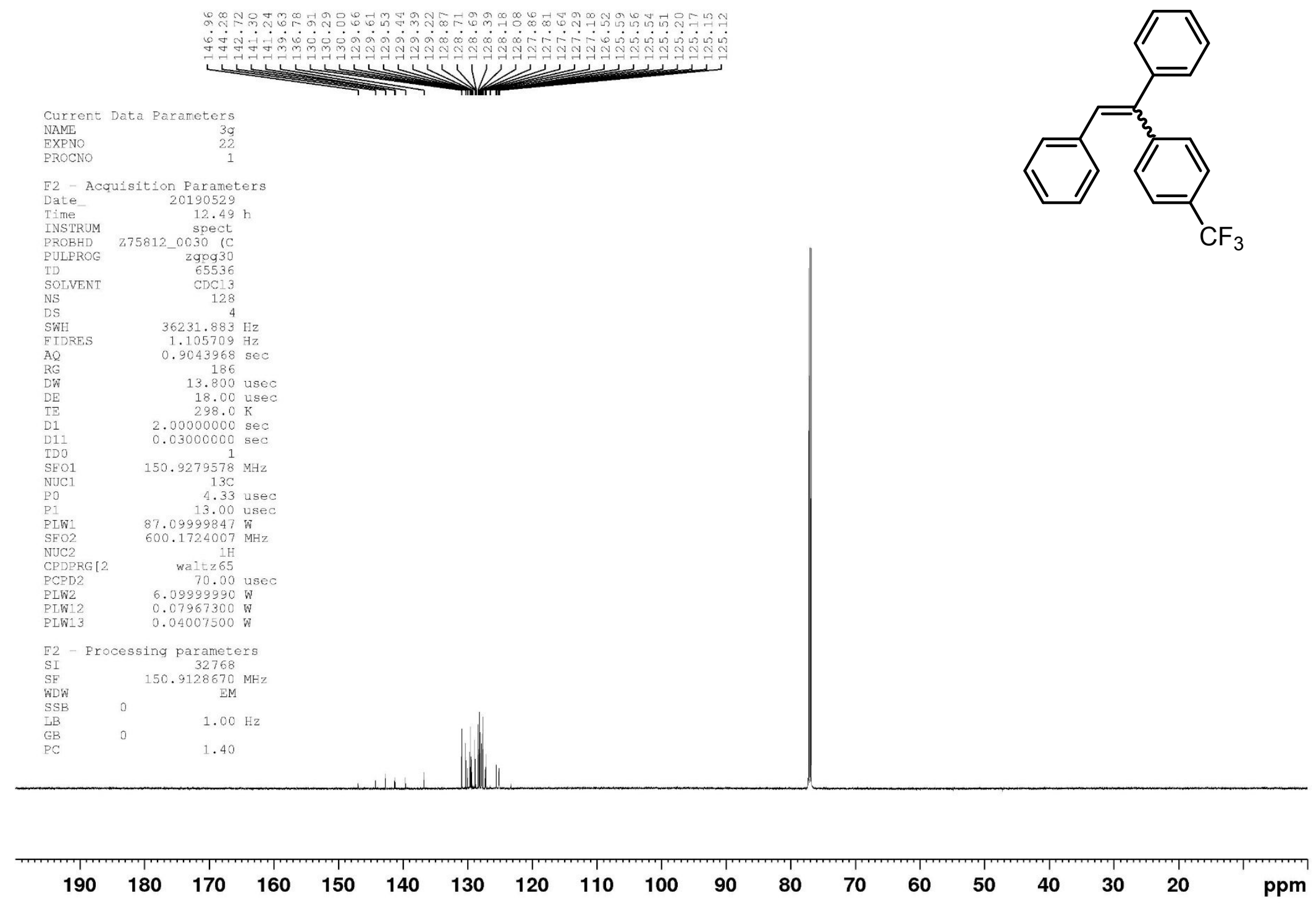


${ }^{1}$ H NMR Spectrum for ( $\left.Z / E\right)$-methyl 4-(1,2-diphenylvinyl)benzoate (3h):

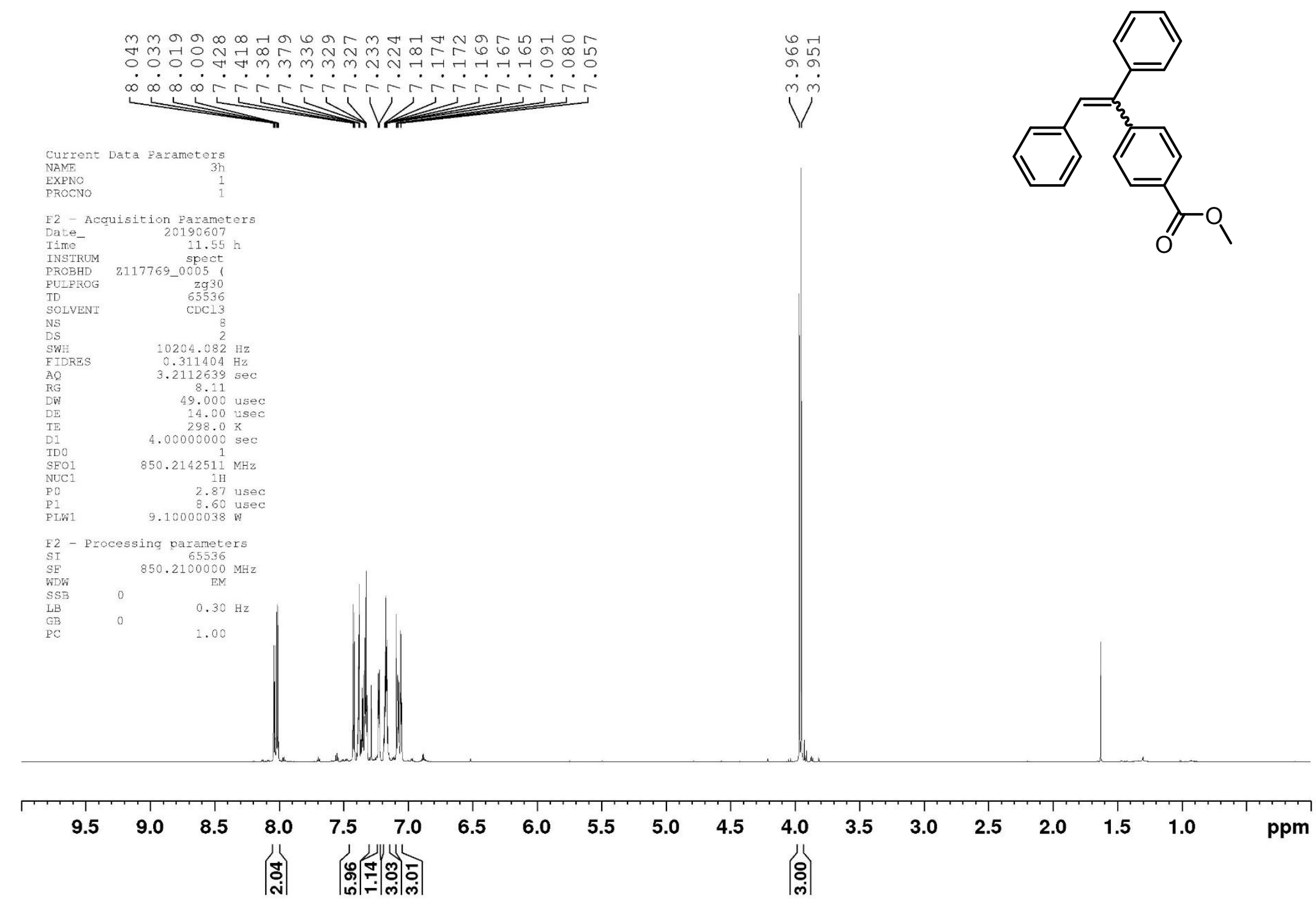


${ }^{13} \mathrm{C}$ NMR Spectrum for $(Z / E)$-methyl 4-(1,2-diphenylvinyl)benzoate (3h):

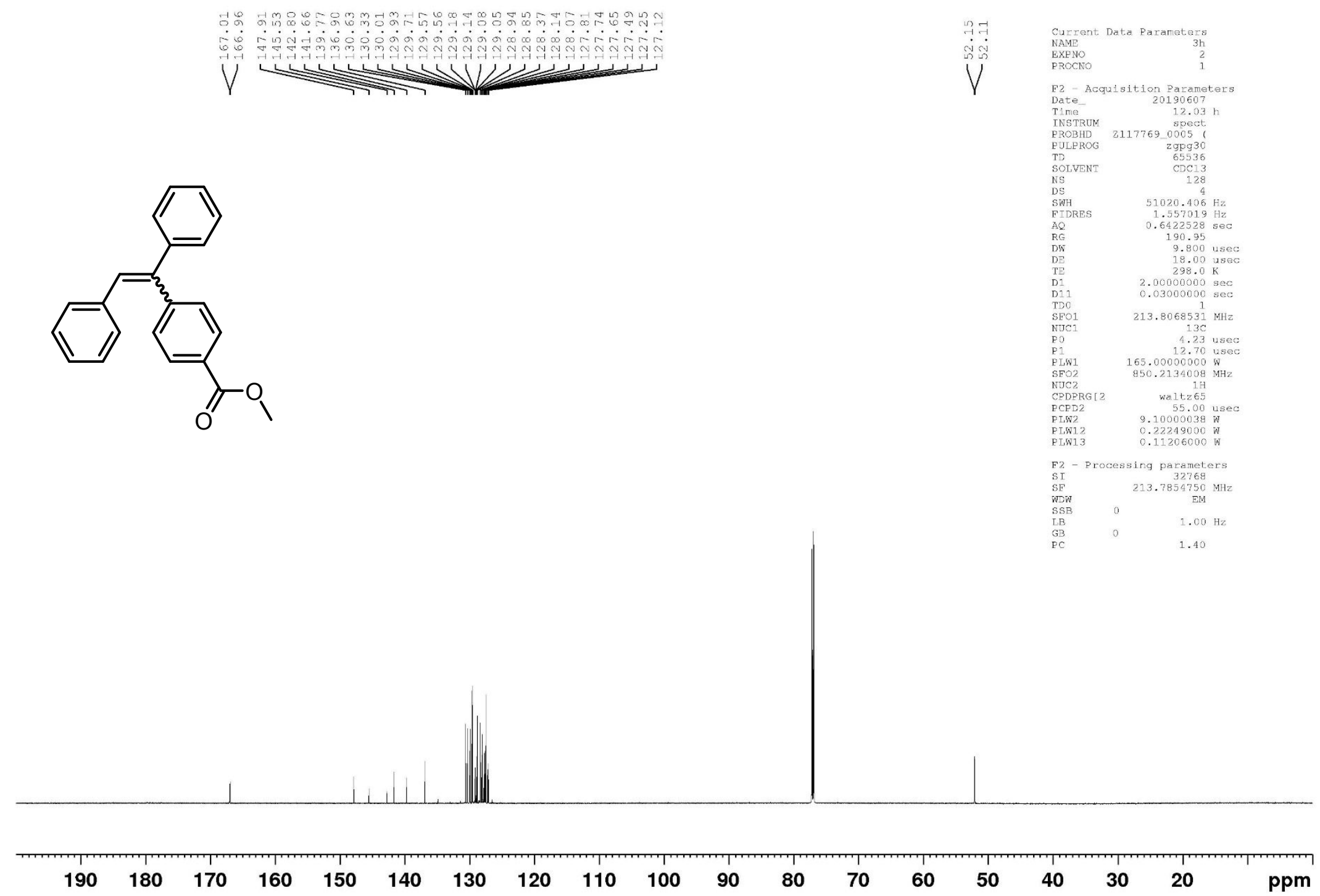


${ }^{1}$ H NMR Spectrum for (Z)-(1-(2,4-dimethylphenyl)ethene-1,2-diyl)dibenzene (3i):

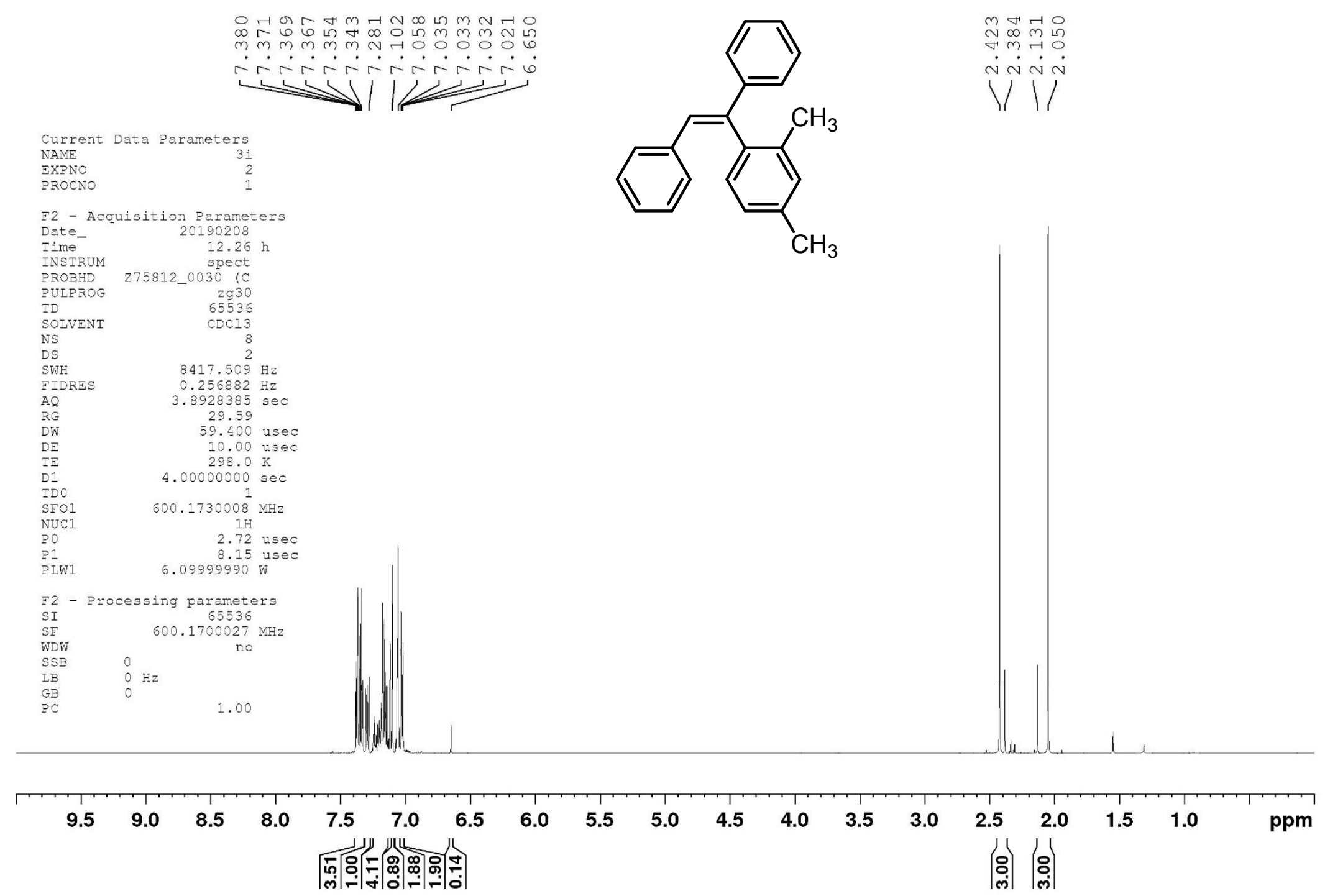


${ }^{13}$ C NMR Spectrum for (Z)-(1-(2,4-dimethylphenyl)ethene-1,2-diyl)dibenzene (3i):

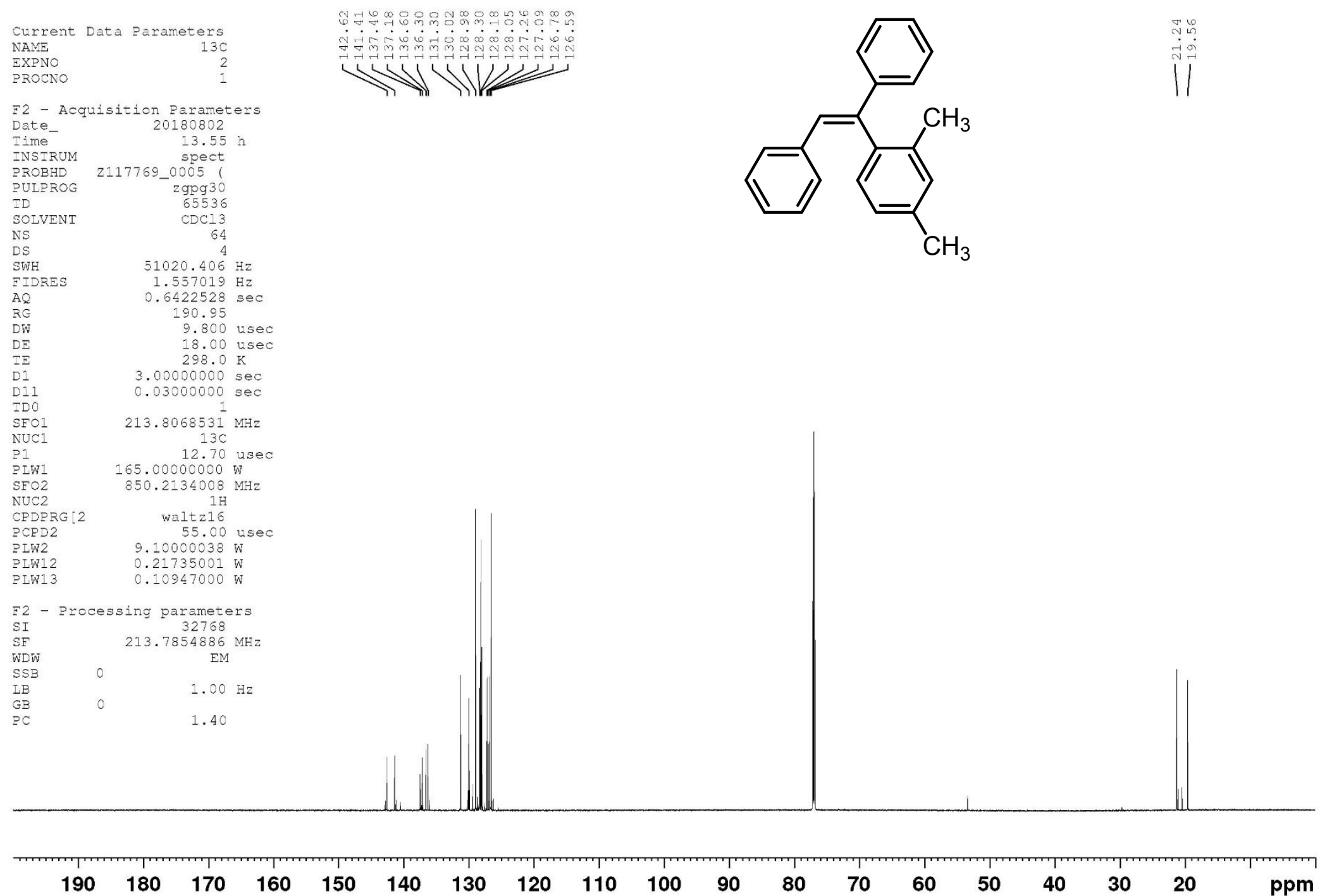


${ }^{1}$ H NMR Spectrum for (Z)-(1-(2,5-dimethylphenyl)ethene-1,2-diyl)dibenzene (3j):

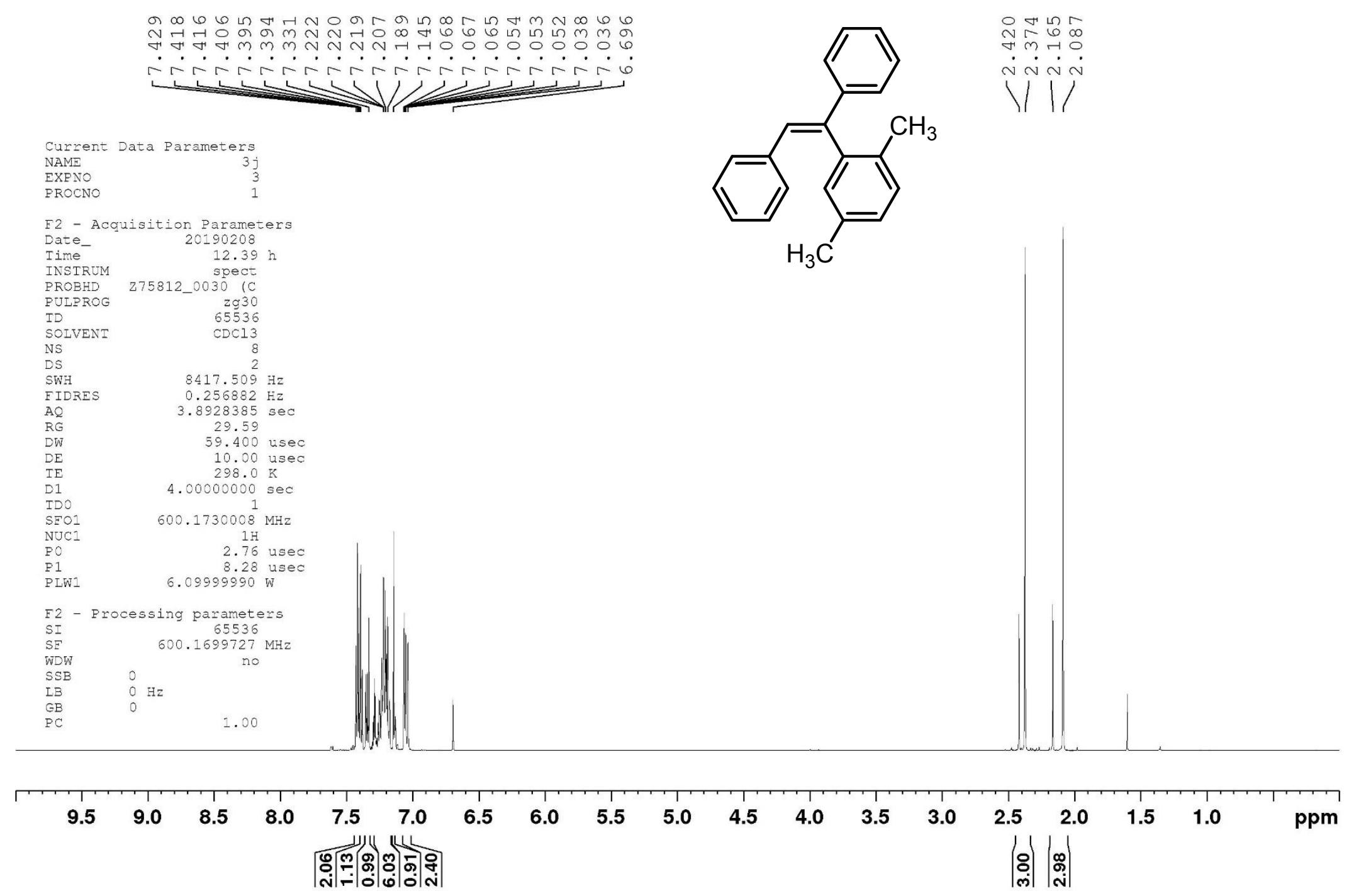


${ }^{13}$ C NMR Spectrum for (Z)-(1-(2,5-dimethylphenyl)ethene-1,2-diyl)dibenzene (3j):

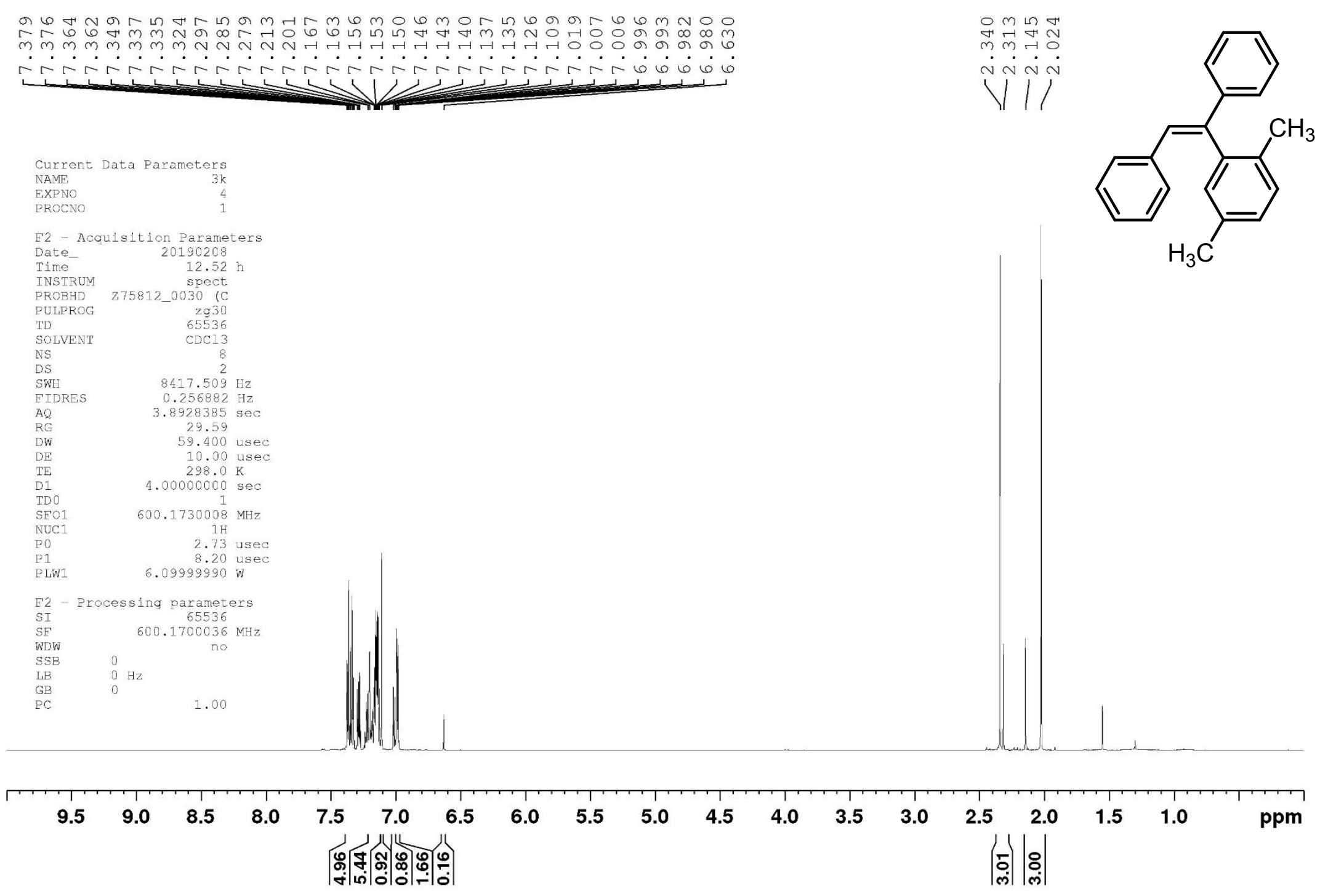


${ }^{1}$ H NMR Spectrum for ( $Z$ )-(1-(2,3-dimethylphenyl)ethene-1,2-diyl)dibenzene (3k):

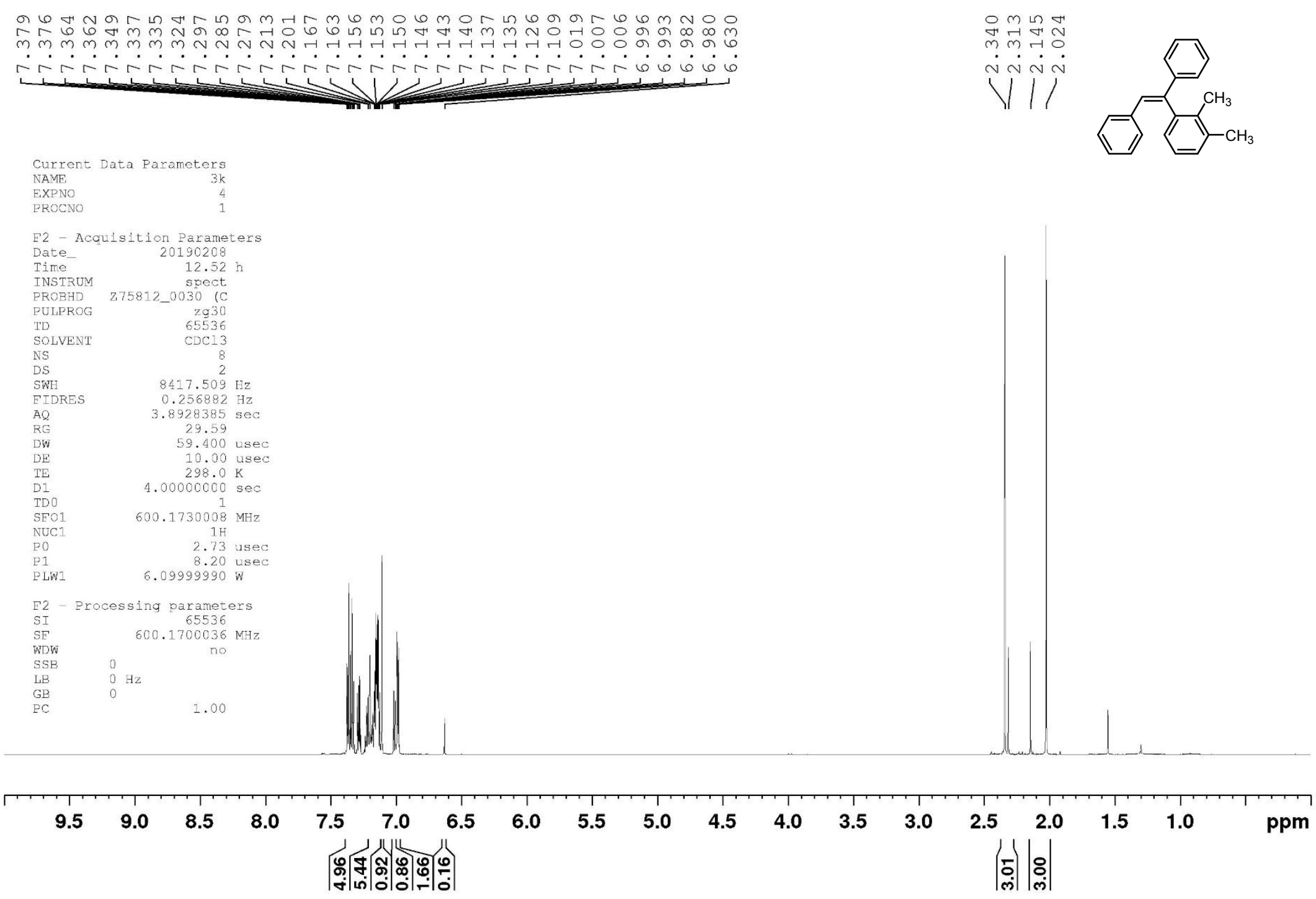


${ }^{13}$ C NMR Spectrum for ( $Z$ )-(1-(2,3-dimethylphenyl)ethene-1,2-diyl)dibenzene (3k):

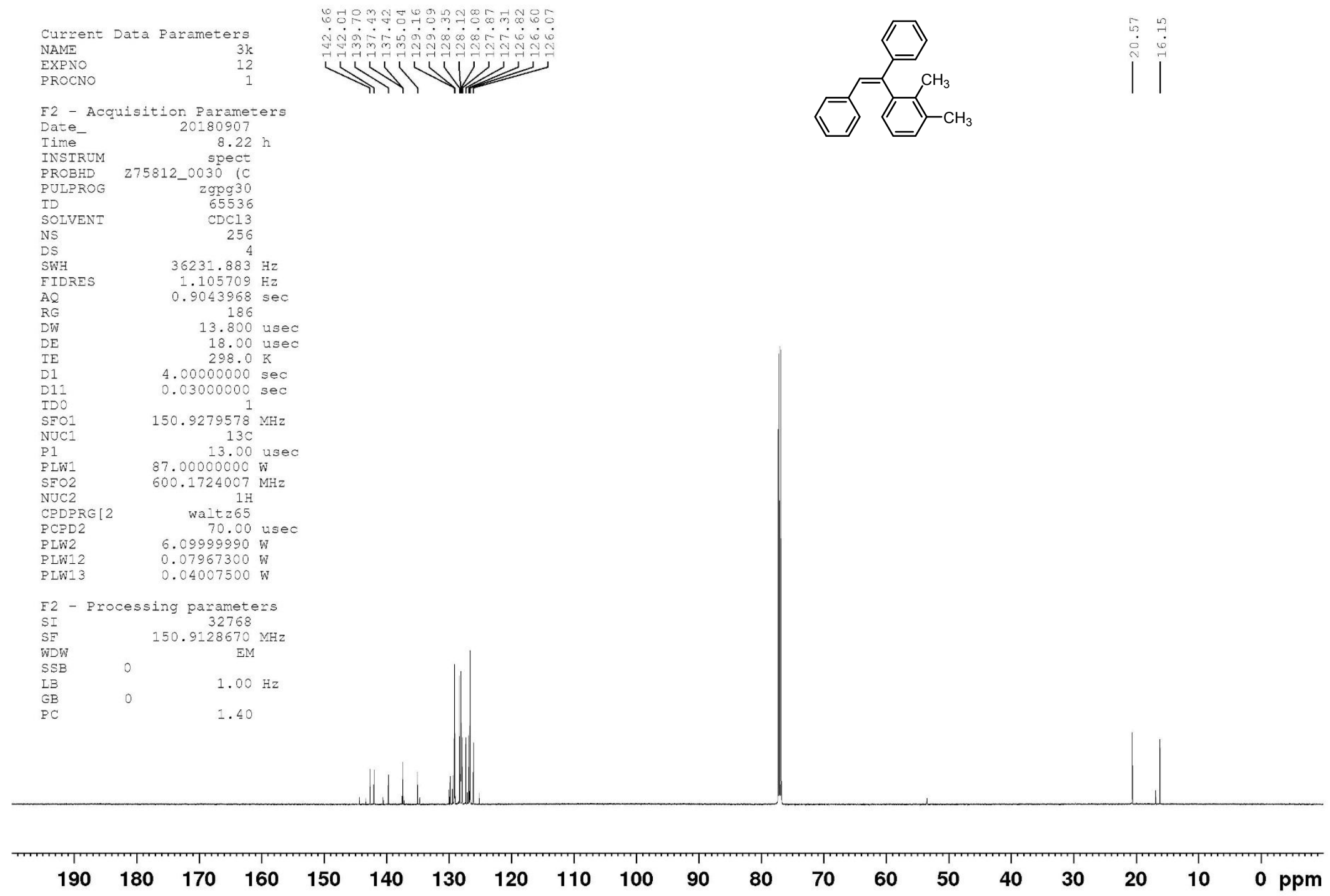


${ }^{1}$ H NMR Spectrum for (Z)-(1-(2-ethylphenyl)ethene-1,2-diyl)dibenzene (3I):

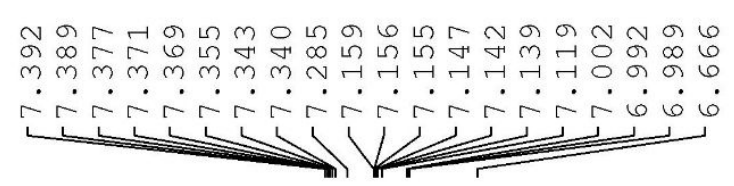

$\circ \infty$ の

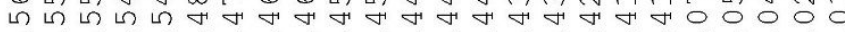
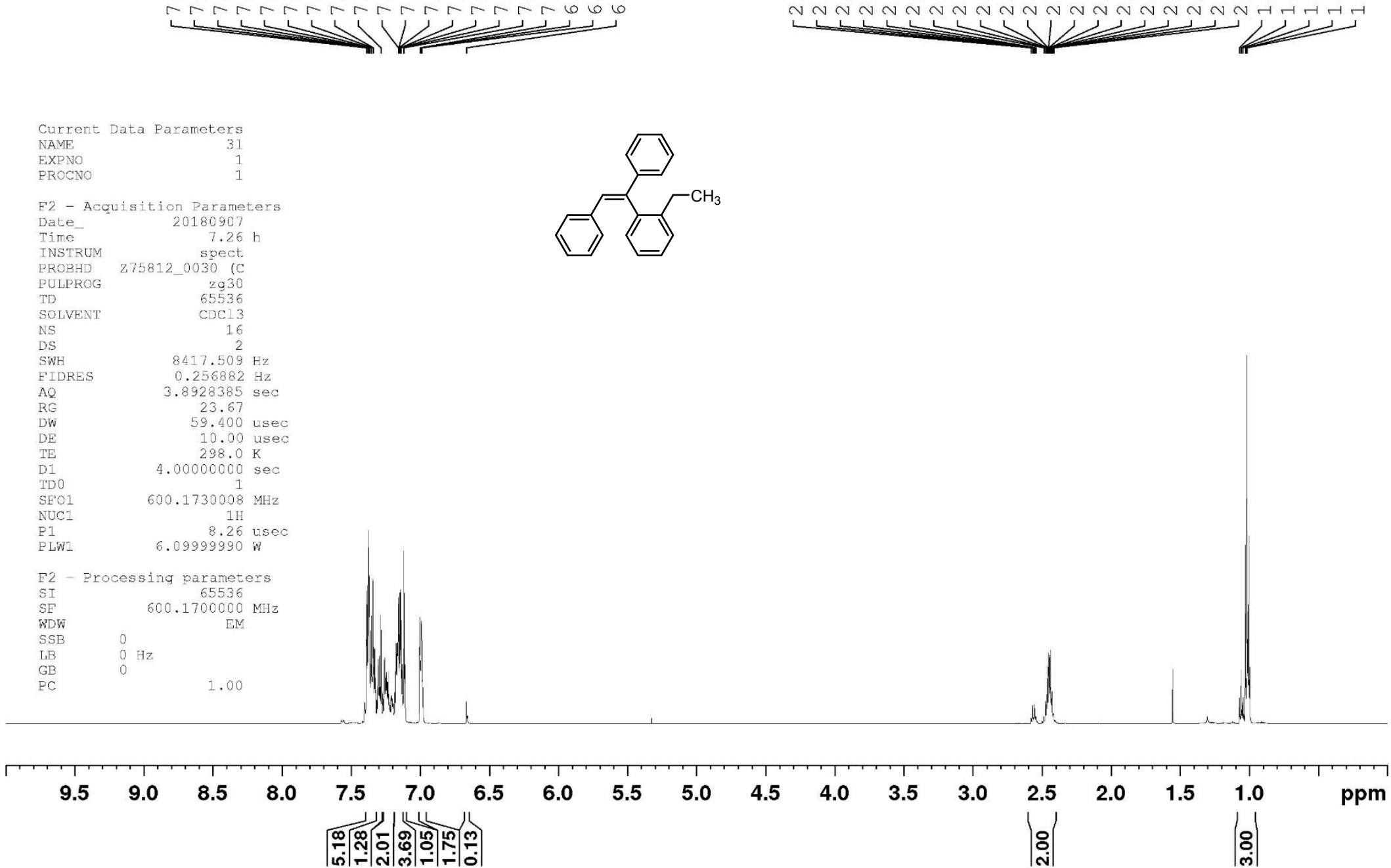

商| 
${ }^{13}$ C NMR Spectrum for (Z)-(1-(2-ethylphenyl)ethene-1,2-diyl)dibenzene (3I):

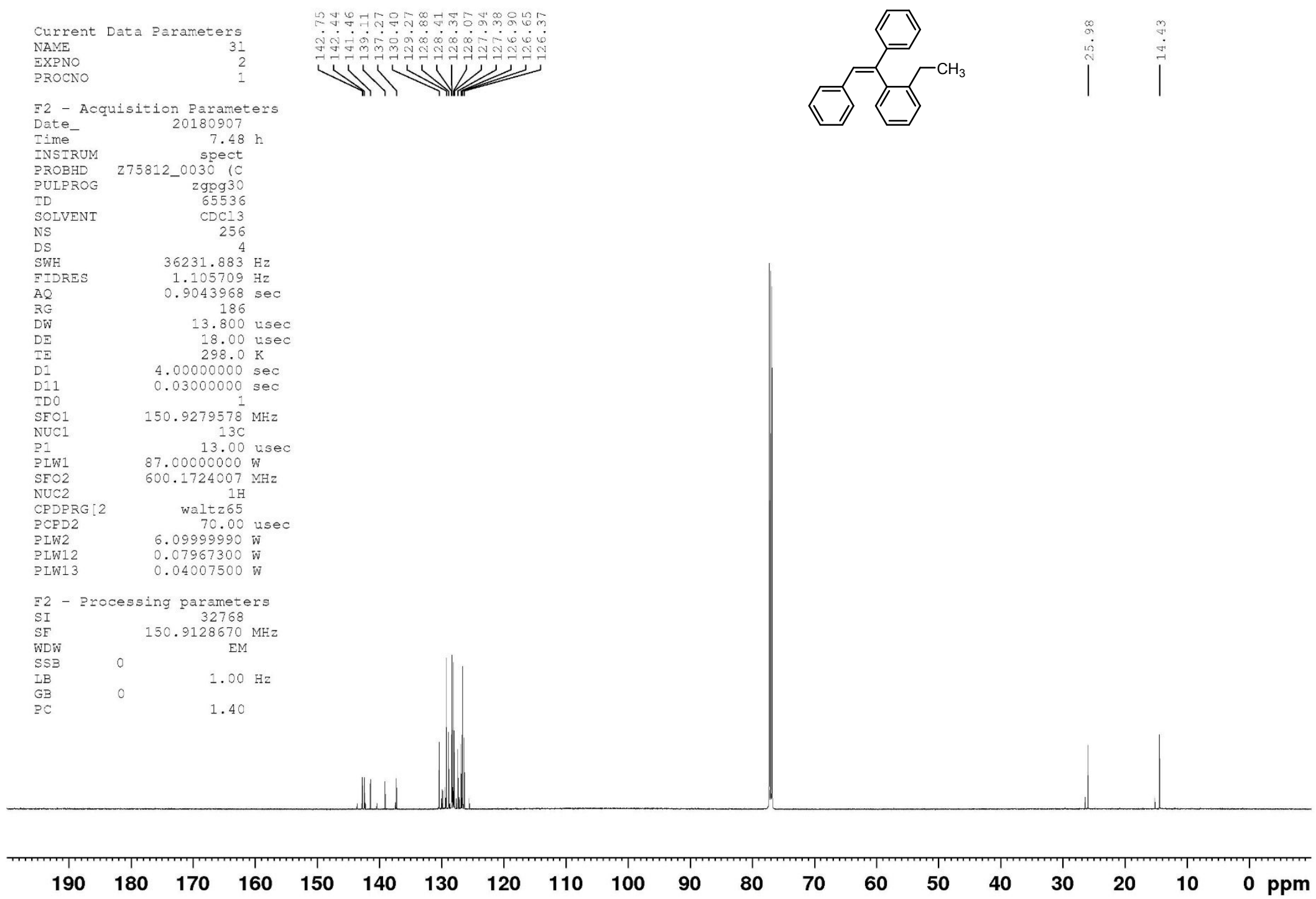


${ }^{1}$ H NMR Spectrum for ( $Z$ )-1-(1,2-diphenylvinyl)naphthalene (3m):

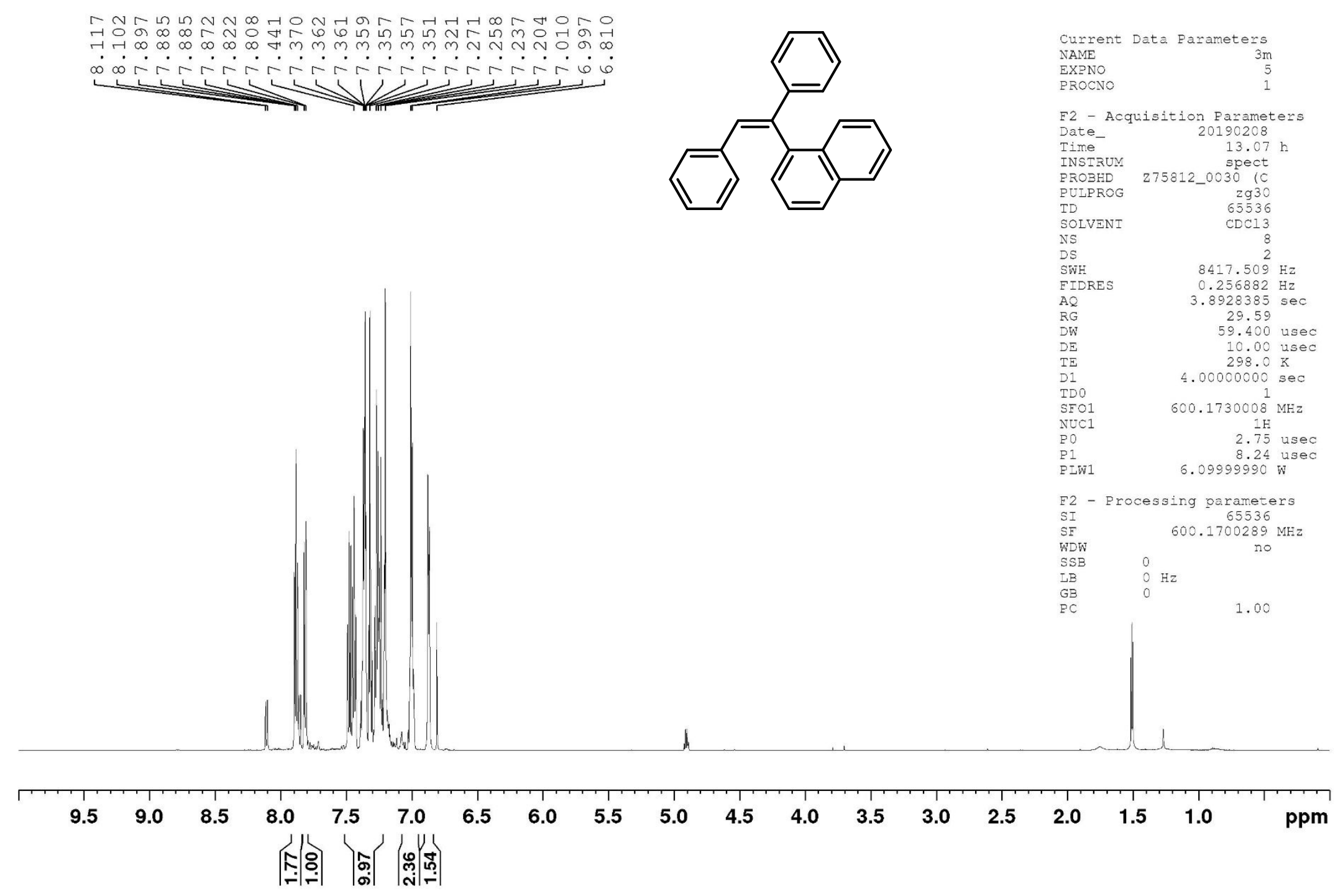


${ }^{13}$ C NMR Spectrum for (Z)-1-(1,2-diphenylvinyl)naphthalene (3m):

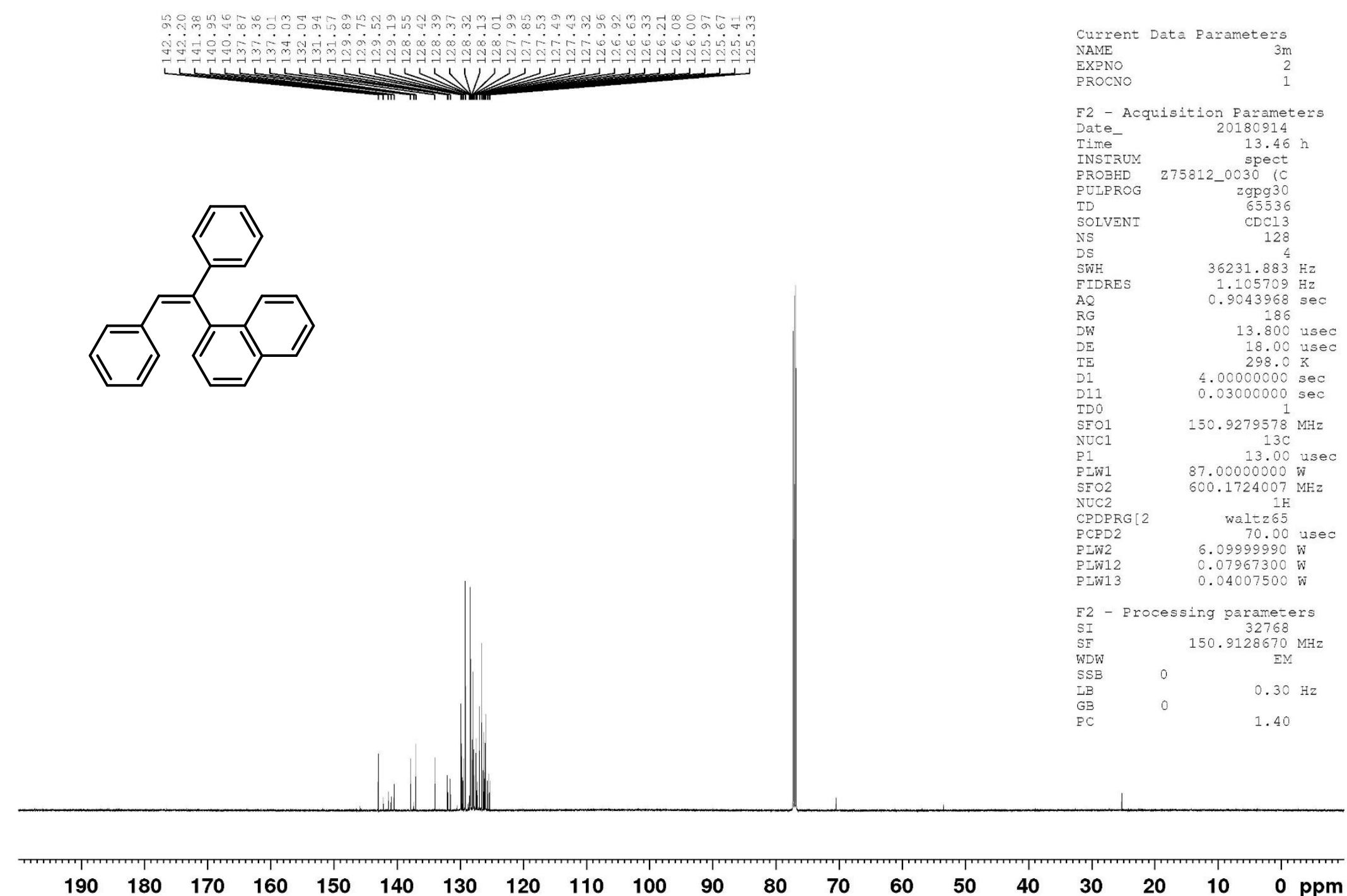


${ }^{1}$ H NMR Spectrum for (Z/E)-(1-(m-tolyl)ethene-1,2-diyl)dibenzene (3n):

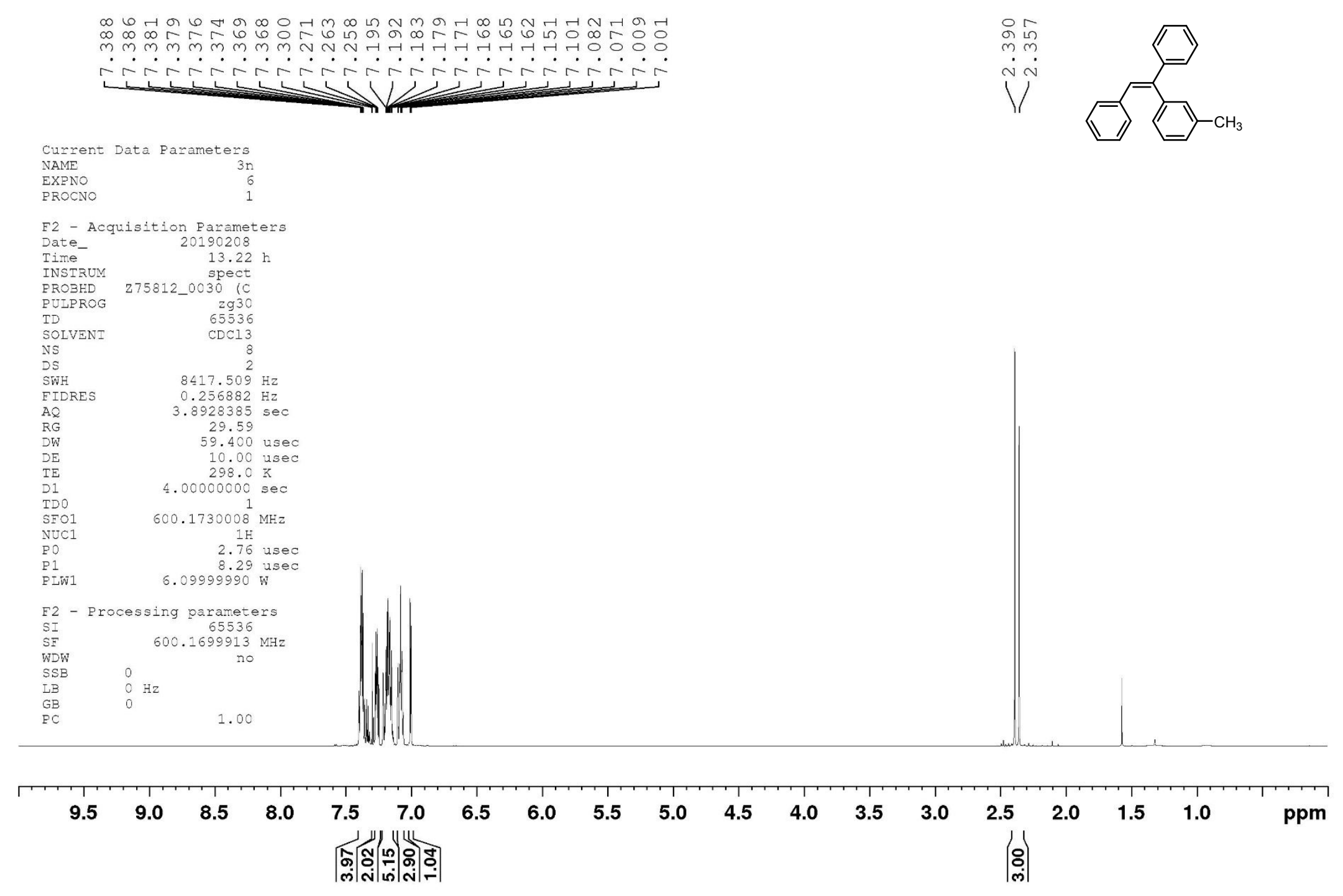


${ }^{13}$ C NMR Spectrum for (Z/E)-(1-(m-tolyl)ethene-1,2-diyl)dibenzene (3n):

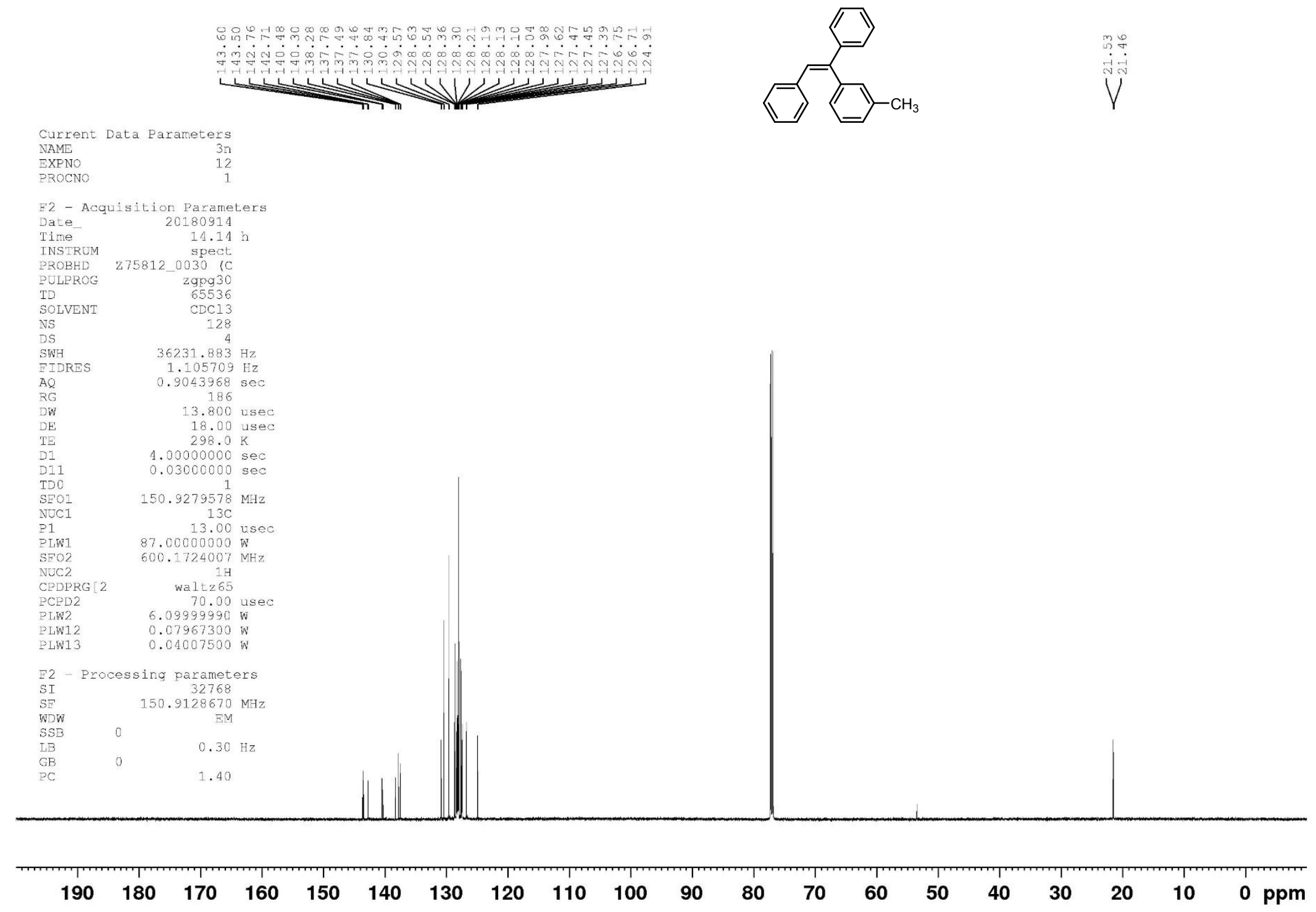


${ }^{1}$ H NMR Spectrum for (Z/E)-(1-(3-ethylphenyl)ethene-1,2-diyl)dibenzene (30):

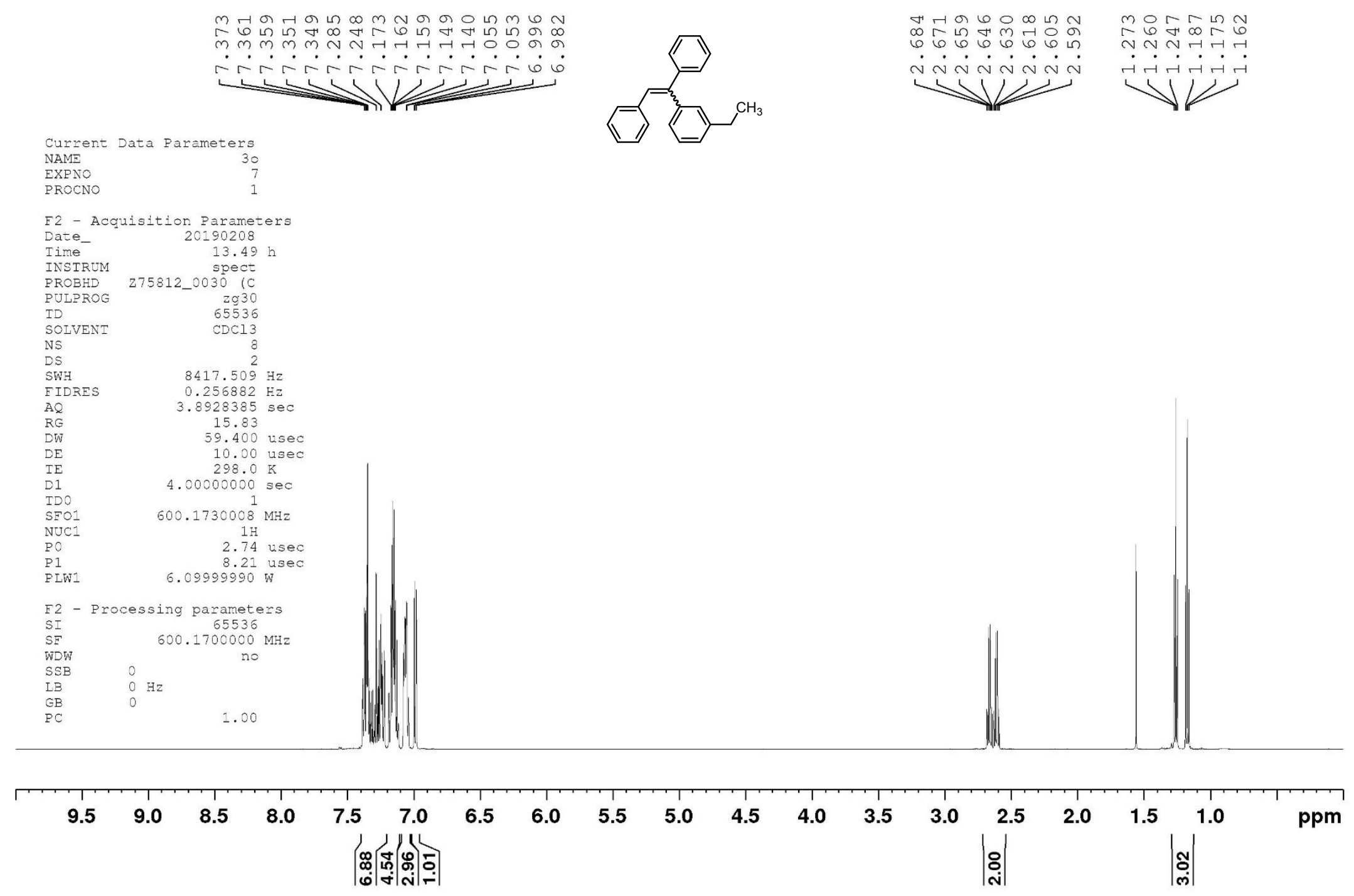


${ }^{13}$ C NMR Spectrum for (Z/E)-(1-(3-ethylphenyl)ethene-1,2-diyl)dibenzene (3o):

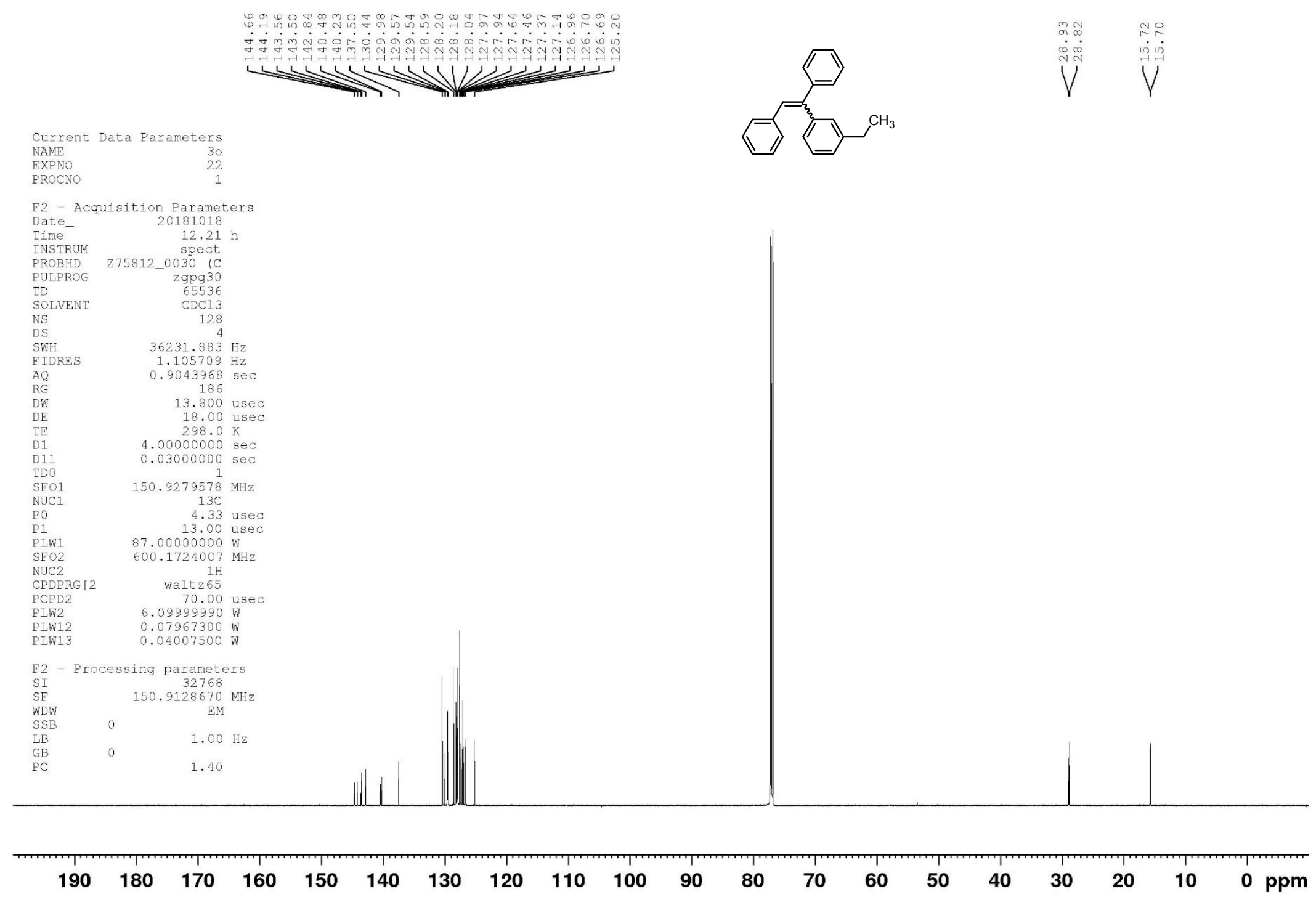


${ }^{1}$ H NMR Spectrum for (Z)-(1-(3,5-di-tert-butylphenyl)ethene-1,2-diyl)dibenzene (3p):

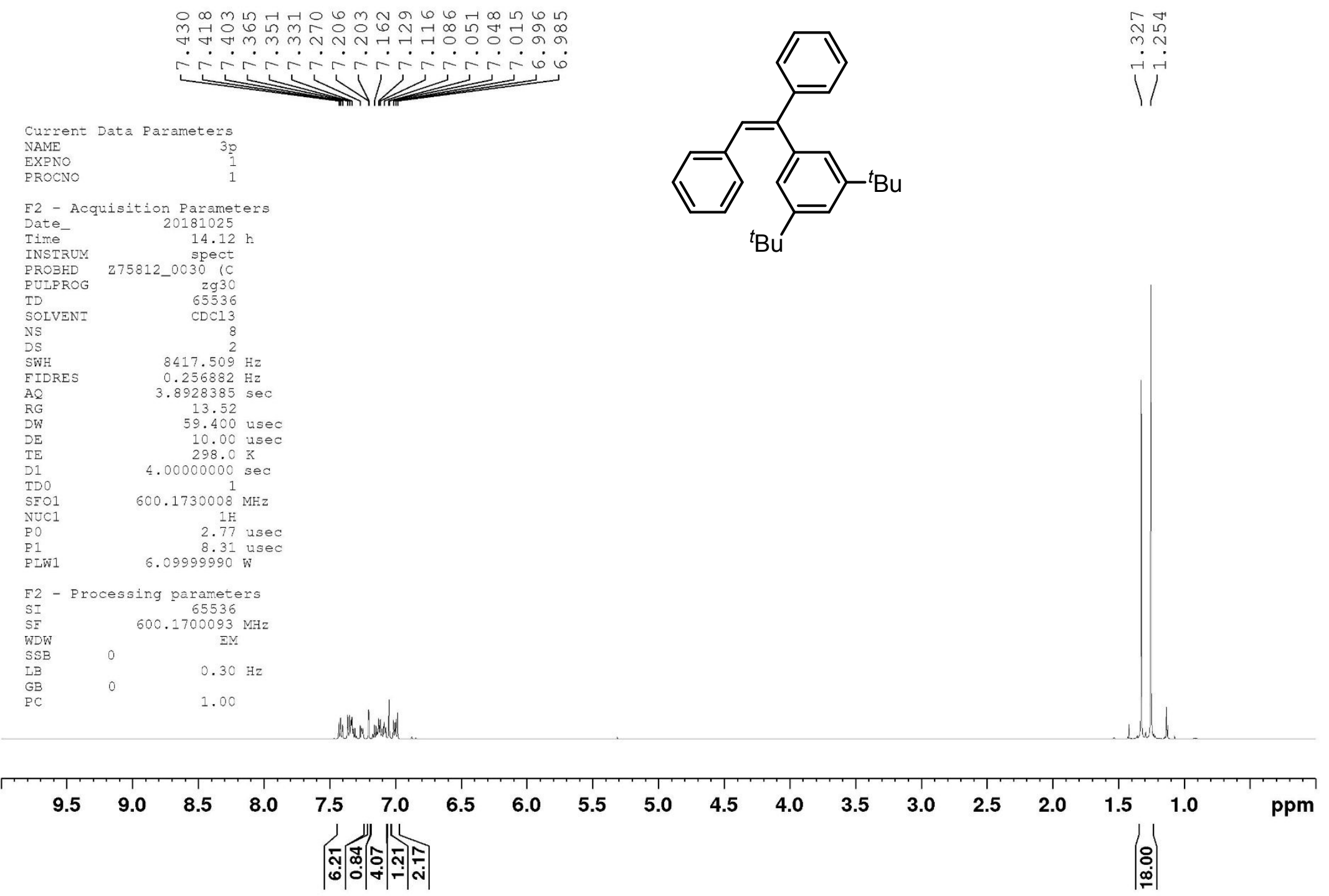




\section{${ }^{13}$ C NMR Spectrum for ( $Z$ )-(1-(3,5-di-tert-butylphenyl)ethene-1,2-diyl)dibenzene (3p):}

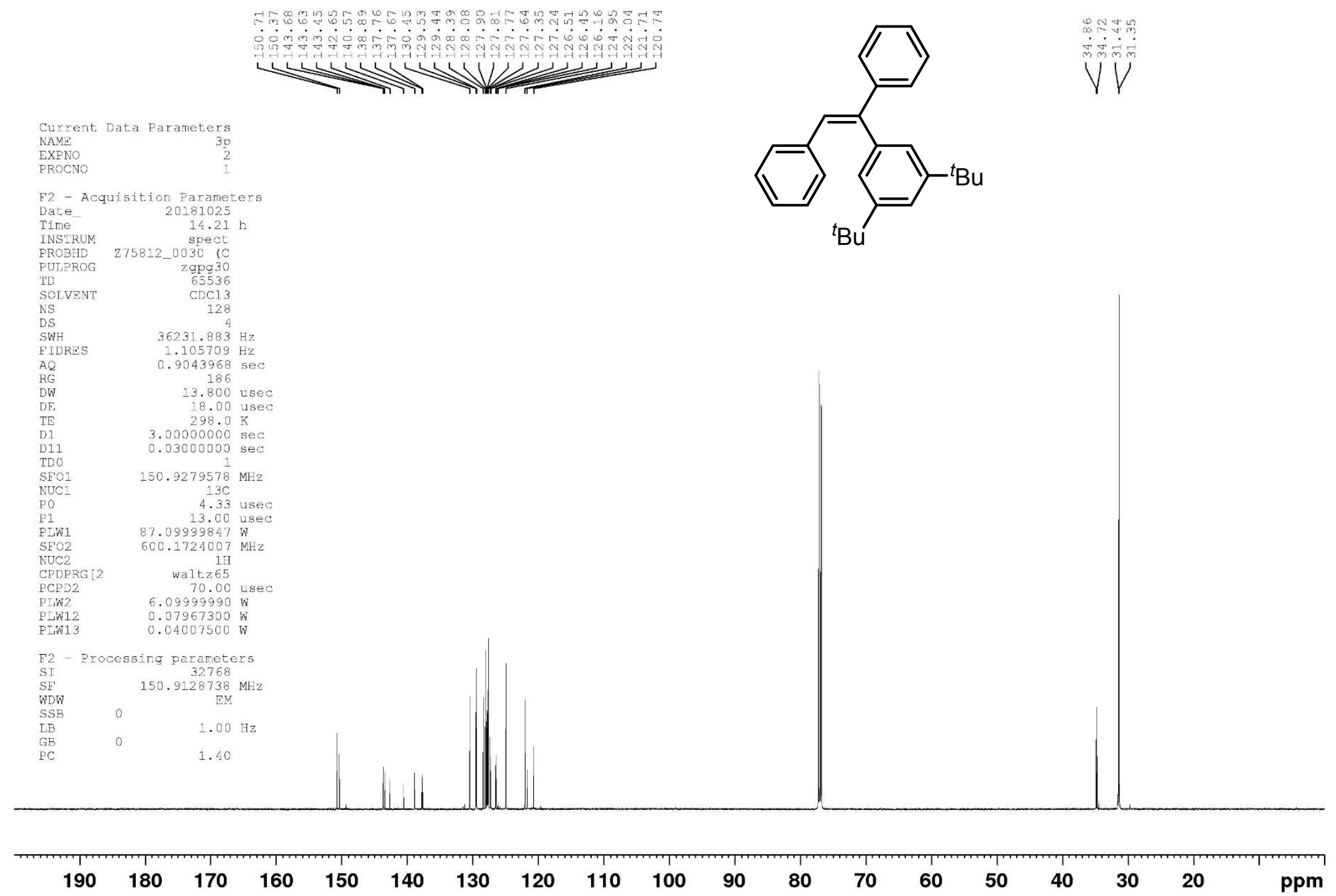


${ }^{1}$ H NMR Spectrum for ( $Z$ )-trimethyl(2-phenyl-2-(o-tolyl)vinyl)silane (3q):

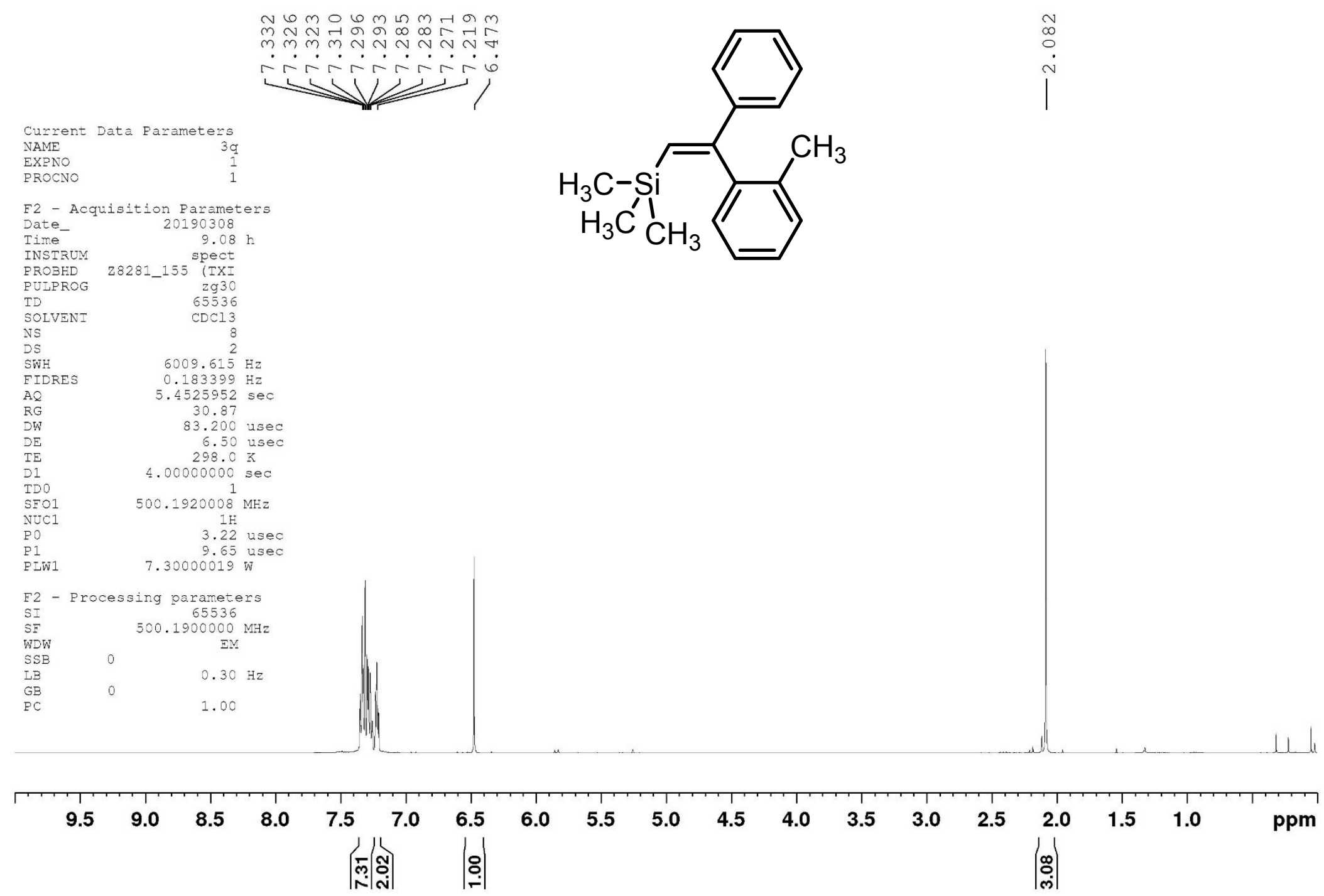


${ }^{13}$ C NMR Spectrum for ( $Z$ )-(1-(3,5-di-tert-butylphenyl)ethene-1,2-diyl)dibenzene (3q):

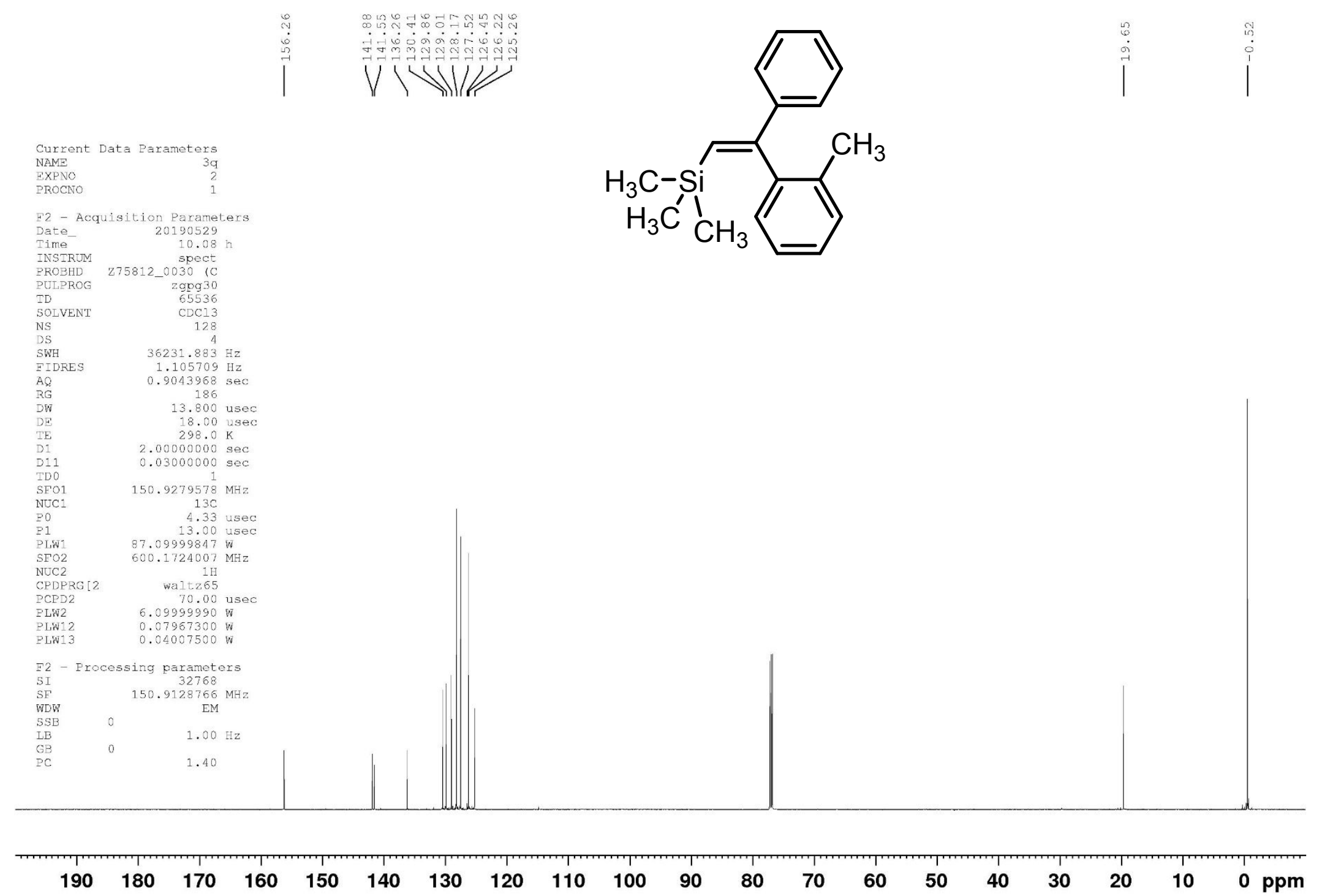


${ }^{1}$ H NMR Spectrum for Ni( ${ }^{t}$ Bubpy)(o-tolyl)Br (5)

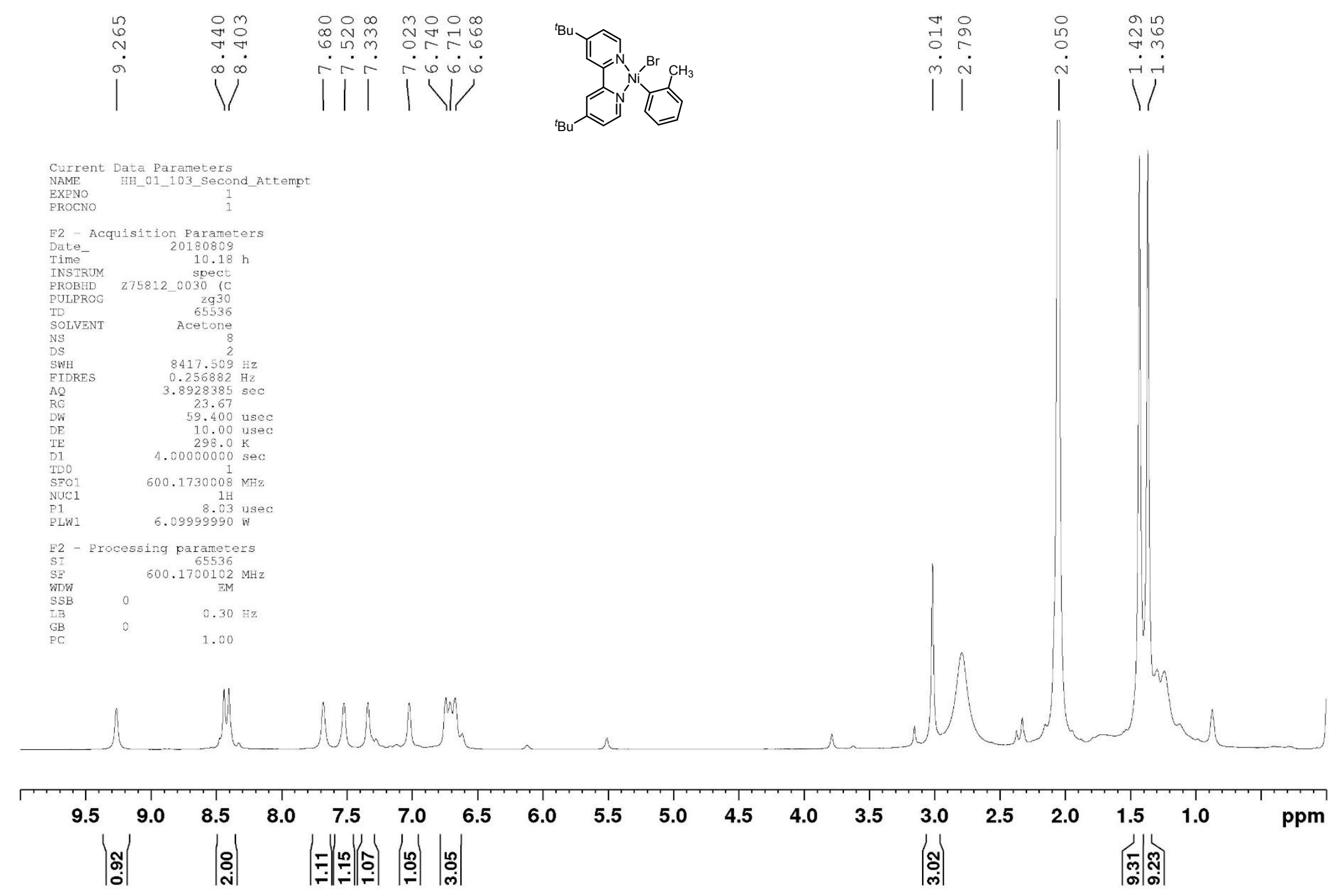

